\title{
Integrin allb $\beta 3$ outside-in signaling activates human platelets through serine 24 phosphorylation of Disabled-2
}

\author{
Hui-Ju Tsai ${ }^{1}$, Ju-Chien Cheng ${ }^{2}$, Man-Leng Kao ${ }^{1}$, Hung-Pin Chiu' ${ }^{1}$, Yi-Hsuan Chiang ${ }^{1}$, Ding-Ping Chen ${ }^{1,3}$,
} Kun-Ming Rau ${ }^{4,5}$, Hsiang-Ruei Liao ${ }^{6,7,8}$ and Ching-Ping Tseng ${ }^{1,3,7,9^{*}}$ (D)

\begin{abstract}
Background: Bidirectional integrin allb $\beta 3$ signaling is essential for platelet activation. The platelet adaptor protein Disabled-2 (Dab2) is a key regulator of integrin signaling and is phosphorylated at serine 24 in eukaryotic cells. However, the mechanistic insight and function of Dab2-serine 24 phosphorylation (Dab2-pSer24) in platelet biology are barely understood. This study aimed to define whether and how Dab2 is phosphorylated at Ser24 during platelet activation and to investigate the effect of Dab2-pSer24 on platelet function.
\end{abstract}

Results: An antibody with confirmed specificity for Dab2-pSer24 was generated. By using this antibody as a tool, we showed that protein kinase C (PKC)-mediated Dab2-pSer24 was a conservative signaling event when human platelets were activated by the platelet agonists such as thrombin, collagen, ADP, 12-O-tetradecanoylphorbol-13-acetate, and the thromboxane A2 activator U46619. The agonists-stimulated Dab2-pSer24 was attenuated by pretreatment of platelets with the RGDS peptide which inhibits integrin outside-in signaling by competitive binding of integrin allb with fibrinogen. Direct activation of platelet integrin outside-in signaling by combined treatment of platelets with manganese dichloride and fibrinogen or by spreading of platelets on fibrinogen also resulted in Dab2-pSer24. These findings implicate that Dab2-pSer24 was associated with the outside-in signaling of integrin. Further analysis revealed that Dab2-pSer24 was downstream of Src-PKC-axis and phospholipase D1 underlying the integrin allbß3 outside-in signaling. A membrane penetrating peptide R11-Ser24 which contained 11 repeats of arginine linked to the Dab2Ser24 phosphorylation site and its flanking sequences (RRRRRRRRRRR ${ }^{19}$ APKAPSKKEKK ${ }^{29}$ ) and the R11-S24A peptide with Ser24Ala mutation were designed to elucidate the functions of Dab2-pSer24. R11-Ser24 but not R11-S24A inhibited agonists-stimulated Dab2-pSer24 and consequently suppressed platelet spreading on fibrinogen, with no effect on platelet aggregation and fibrinogen binding. Notably, Ser24 and the previously reported Ser723 phosphorylation (Dab2-pSer723) occurred exclusively in a single Dab2 molecule and resulted in distinctive subcellular distribution and function of Dab2. Dab2-pSer723 was mainly distributed in the cytosol of activated platelets and associated with integrin inside-out signaling, while Dab2-pSer24 was mainly distributed in the membrane fraction of activated platelets and associated with integrin outside-in signaling.

\footnotetext{
*Correspondence: ctseng@mail.cgu.edu.tw

1 Department of Medical Biotechnology and Laboratory Science, College

of Medicine, Chang Gung University, Taoyuan 333, Taiwan, Republic

of China

Full list of author information is available at the end of the article
}

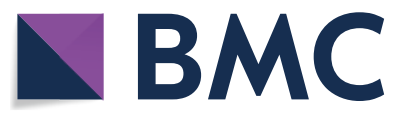

(c) The Author(s) 2021. This article is licensed under a Creative Commons Attribution 4.0 International License, which permits use, sharing, adaptation, distribution and reproduction in any medium or format, as long as you give appropriate credit to the original author(s) and the source, provide a link to the Creative Commons licence, and indicate if changes were made. The images or other third party material in this article are included in the article's Creative Commons licence, unless indicated otherwise in a credit line to the material. If material is not included in the article's Creative Commons licence and your intended use is not permitted by statutory regulation or exceeds the permitted use, you will need to obtain permission directly from the copyright holder. To view a copy of this licence, visit http://creativeco mmons.org/licenses/by/4.0/. The Creative Commons Public Domain Dedication waiver (http://creativecommons.org/publicdomain/ zero/1.0/) applies to the data made available in this article, unless otherwise stated in a credit line to the data. 
Conclusions: These findings demonstrate for the first time that Dab2-pSer24 is conservative in integrin allb $\beta 3$ outside-in signaling during platelet activation and plays a novel role in the control of cytoskeleton reorganization and platelet spreading on fibrinogen.

Keywords: Disabled-2, Phosphorylation, Platelet activation, Outside-in signaling

\section{Background}

Platelet activation is crucial for stopping blood loss following vessel wall damage and it plays a pivotal role in the onset of myocardial infarction and other thrombotic diseases. Bidirectional signaling of the platelet transmembrane receptor integrin $\alpha \operatorname{IIb} \beta 3$ is essential in the course of platelet activation [1]. Exposure of the circulating platelets to collagen and von Willebrand factor derived from the damaged endothelial cells turns on integrin inside-out signaling leading to an increase in the binding affinity of integrin $\alpha \operatorname{IIb} \beta 3$ to soluble fibrinogen [2]. Fibrinogen binding further activates integrin $\alpha \operatorname{IIb} \beta 3$ outside-in signaling that subsequently causes cytoskeletal remodeling and clot retraction to prevent blood loss [3-5].

Integrin $\alpha \operatorname{IIb} \beta 3$ bidirectional signaling is tightly regulated by different types of molecules including transmembrane proteins, protein kinases and adaptor proteins. Various signaling pathways are involved in the transmission of integrin $\alpha \operatorname{IIb} \beta 3$ inside-out signaling. The agonists of thrombin, thromboxane A2 (TXA2), and ADP bind to their respective $G$ protein-coupled receptors and activate either a $G_{\alpha q}$-dependent increase in intracellular calcium and protein kinase C (PKC) activity, $\mathrm{G}_{\alpha 12 / 13}$-dependent Rho activation, $G_{\alpha i}$-dependent inhibition of adenylyl cyclase, and/or $\mathrm{G}_{\beta \gamma}$-dependent phosphoinositide 3-kinase-Akt activation [2, 3, 6-8]. Collagen interacts with glycoprotein VI and recruits Src and Syk to the plasma membrane followed by tyrosine phosphorylation of downstream substrates required for platelet activation $[3,9]$. The phosphorylation and talin binding cause conformational change of the receptor and transform integrin from the resting to the active stage, which elicits high affinity binding activity to fibrinogen. The binding of fibrinogen further activates integrin outside-in signaling, causing the association of the cytoplasmic domain of integrin $\alpha \operatorname{IIb} \beta 3$ with actin filaments, intracellular signaling molecules, and adaptor proteins including talin, vinculin, zyxin, paxillin, filamin, $\alpha$-actinin, and nonmuscle myosin IIA and IIB [10-13]. Therapeutic agents directly targeting $\alpha \operatorname{IIb} \beta 3$ are clinically valuable in the treatment of thrombotic diseases [14-16]. However, the $\alpha I I b \beta 3$ blockers may still cause conformational changes of integrin and activate outside-in signaling with a risk of hemorrhagic complications $[5,17]$. A better understanding of the components and mechanism of $\alpha \operatorname{IIb} \beta 3$ bidirectional signaling, in particular outside-in signaling, may provide novel and safer therapeutic targets without affecting normal hemostasis.

Disabled-2 (Dab2) is an adaptor protein expressed abundantly in human platelets [18-21]. Dab2 is distributed in the cytosol and $\alpha$-granules in human platelets [19]. It is released from the $\alpha$-granules and binds to either integrin $\alpha \mathrm{IIb}$ or phospholipid sulfatide in response to platelet activation, thereby playing a role in platelet-fibrinogen and platelet-leukocyte adhesion and aggregation [19, 22-24]. Dab2 regulates insideout signaling of integrin $\alpha \operatorname{IIb} \beta 3$ by playing a selective role in thrombin-stimulated $G_{\alpha 12 / 13}$-mediated RhoAROCK activation in mouse platelets [21]. Thrombin also induces Dab2 phosphorylation at Ser723 for transmitting integrin inside-out signaling and causing Dab2Cbl-interacting protein of $85 \mathrm{kDa}$ (CIN85) complex disassociation during human platelet activation [20].

In eukaryotic cells, additional Dab2 phosphorylation sites have been identified by mass spectrometry and phosphoamino acid analysis [18, 25-34]. PKC-mediated Dab2-Ser24 phosphorylation inhibits 12-O-tetradecanoylphorbol-13-acetate (TPA)-induced AP-1 activity [28] and is involved in TPA-induced megakaryocytic differentiation of human leukemic K562 cells for maintaining integrin $\alpha \operatorname{IIb} \beta 3$ in an inactivated state [18]. Dab2-Ser249 phosphorylation is detected in resting and activated platelets induced by ADP but not thrombin [30]. A cluster of phosphorylation sites at residues 221231, 324-329, and 393-401 are associated with either cell cycle arrest in mitosis or nuclear localization of Dab2 [27, 31-34]. However, the lack of phospho-Dab2 specific antibodies targeting the phosphorylation sites hampers the comprehensive analysis of these phosphorylation events in platelets and other cellular systems.

The Dab2-Ser24 phosphorylation site is highly conserved among different species. A phospho-Ser24-specific anti-Dab2 antibody was generated for elucidating the status and function of Dab2-Ser24 phosphorylation in human platelets. We defined in this study the Src-PKC signaling axis- and activated phospholipase D1 (PLD1)-mediated Dab2-Ser24 phosphorylation is a common event in agonist-stimulated human platelets and plays a pivotal function in integrin $\alpha \operatorname{IIb} \beta 3$ outsidein signaling. 


\section{Results}

Generation and characterization

of the phospho-Ser24-specific anti-Dab2 antibody

Dab2-Ser24 and its flanking sequences are conserved among different species (Table 1). A phospho-Ser24specific anti-Dab2 (anti-p-Dab2 (S24)) antibody was generated to facilitate the detection and analysis of Dab2-Ser24 phosphorylation in human platelets. Dot blot analysis revealed that the purified anti-p-Dab2 (S24) antibody recognized the phosphorylated peptide (P-pep) but not the non-phosphorylated peptide (NPpep) (Fig. 1a).

Dab2-Ser24 is phosphorylated in eukaryotic cells treated with TPA [28]. The specificity of the anti-pDab2 (S24) antibody was confirmed by analysis of the lysates from TPA-treated 293T cells expressing the HA-Dab2 or the HA-Dab2-S24A plasmid, which encodes the HA-tag wild type and the serine to alanine mutation at the 24th amino acid residue of Dab2, respectively. The anti-p-Dab2 (S24) antibody was able to detect a band corresponding to Dab2 Ser24 phosphorylation in lysates from cells expressing HA-Dab2, but not HA-Dab2-S24A (Fig. 1b).

TPA treatment of human platelets under constant mixing in a thermomixer resulted in the retardation of Dab2 mobility when analyzed by sodium dodecyl sulfate-polyacrylamide gel electrophoresis (SDS-PAGE)(Fig. 1c). Western blotting using the anti-p-Dab2 (S24) antibody revealed that TPA induced Dab2-Ser24 phosphorylation in human platelets. The intensity of the protein band corresponding to Dab2-Ser24 phosphorylation was diminished when the antibody was pre-incubated with the P-pep but not the NP-pep peptide (Fig. 1d). These data indicate that an antibody that specifically recognizes Ser24 phosphorylation of Dab2 was generated and that TPA induced Dab2 phosphorylation at Ser24 in human platelets.
Dab2-Ser24 phosphorylation is a conservative signaling during platelet activation

To elucidate whether or not Dab2-Ser24 phosphorylation is a common signaling event during platelet activation, human platelets were treated with different platelet agonists including thrombin, PAR1 peptide, PAR4 peptide, collagen, U46619, ADP or TPA under constant stirring in an aggregometer, which elicited greater platelet activation compared to the reaction under constant mixing in a thermomixer (data not shown). All agonists caused a dose-dependent increase in platelet aggregation (Fig. 1e). Dab2-Ser24 phosphorylation was induced when human platelets were treated with different platelet agonists. Dab2 underwent degradation and resulted in degradation products with the molecular weights of $38-45 \mathrm{kDa}$ (Fig. 1f). TPAstimulated platelets were used for elucidating whether or not Dab2 degradation is associated with Ser24 phosphorylation. The proteasome inhibitor MG-132 at high concentrations (30 and $50 \mu \mathrm{M}$ ) suppressed Dab2-Ser24 phosphorylation and degradation but not Dab2-Ser723 phosphorylation and platelet aggregation (Fig. 1g-i). These data indicate that Dab2-Ser24 phosphorylation is a common event during platelet activation and is associated with the degradation of Dab2 but not with platelet aggregation.

\section{Dab2-Ser24 is phosphorylated by PKCs during platelet activation}

A peptide containing Ser24 and its flanking sequences (APS ${ }^{24}$ KKEKKKGSEKTD) is a PKC substrate [28]. Platelets pre-treated with the pan-PKC inhibitor staurosporine, attenuated agonist-stimulated platelet aggregation (Fig. 2a) and inhibited Dab2-Ser24 phosphorylation $(\mathrm{p}<0.001)$ and degradation (Fig. 2b, 2c). Human platelets express PKC $\alpha, \beta I I, \delta, \theta$, and $\zeta[35]$. A GST-recombinant

Table 1 Dab2-Ser24 and its flanking sequences are conserved among different species

\begin{tabular}{|c|c|c|c|c|}
\hline Species & AA\# & P-Site & Sequence & GenBank accession number \\
\hline Human & 770 & S24 & ${ }^{18}$ AAPKAPSKKEKKK ${ }^{30}$ & NP_001334.2 \\
\hline Chimpanzee & 770 & S24 & ${ }^{18}$ AAPKAPSKKEKKK ${ }^{30}$ & JAA20332.1 \\
\hline Rhesus Macaque & 770 & S24 & ${ }^{18}$ AAPKAPSKKEKKK ${ }^{30}$ & AFI34301.1 \\
\hline Dog & 770 & S24 & ${ }^{18}$ AAPKAPSKKEKKK ${ }^{30}$ & XP_536493.2 \\
\hline Platypus & 758 & S24 & ${ }^{18}$ TAPKVPSKKEKKK ${ }^{30}$ & XP_001507342.2 \\
\hline Rat & 768 & S24 & ${ }^{18}$ AAPKAPSKKEKKK ${ }^{30}$ & NP_077073.1 \\
\hline Mouse & 766 & S24 & ${ }^{18}$ AAPKAPSKKEKKK ${ }^{30}$ & NP_075607.2 \\
\hline Hamster & 765 & S24 & ${ }^{18}$ AAPKVPSKKEKKK ${ }^{30}$ & XP_003503146.1 \\
\hline Chicken & 715 & S26 & ${ }^{20} \mathrm{PPKAQTSKKEKKK}{ }^{32}$ & XP_015133025.1 \\
\hline Frog & 555 & S24 & ${ }^{18}$ PTAKPPSKKEKKK ${ }^{30}$ & NP_001165652.1 \\
\hline Zebra Danio & 668 & $\mathrm{~S} 21$ & ${ }^{15}$ PPFKTPSKKEKKK ${ }^{27}$ & XP_001920879.3 \\
\hline
\end{tabular}


protein corresponding to the N-terminus of Dab2 (GSTDab2N, amino acid 1-234) was phosphorylated by all PKC isoforms as seen with the in vitro protein kinase assay with PKC $\zeta$ being the least effective (Fig. 2d). Ser24 in the full-length wild type HA-tag Dab2 recombinant protein (HA-Dab2-S24) was phosphorylated by PKC $\alpha$, $\beta I I, \delta$ and $\theta$, but not PKC $\zeta$ as seen with the in vitro immunocomplex protein kinase assay (Fig. 2e). This phosphorylation was abolished when Ser24 was mutated to Ala24 (HA-Dab2-S24A). These data support the perception that PKC $\alpha, \beta I I, \delta$ and $\theta$ are responsible for Ser24 phosphorylation of Dab2.

\section{Distinct phosphorylation of Dab2-Ser24 and -Ser723 in platelet activation}

Subcellular fractionation analysis of resting and thrombin- or PAR1 peptide-stimulated platelets revealed that Dab2 was present in the cytosolic and membrane fractions of resting and agonist-stimulated human platelets (Fig. 3a). Integrin $\alpha \mathrm{IIb}$ and GAPDH were used as a marker of the membrane and cytosolic fractions of platelet lysates, respectively [36, 37]. Ser24-phosphorylated Dab2 was increased in thrombin- and PAR1 peptidestimulated platelets and was mainly found in the membrane fraction, while Ser723-phosphorylated Dab2 was mainly found in the cytosolic fraction (Fig. 3a). 293T cells were transfected with either HA-Dab2-S24 or HA-Dab2S24A expression plasmids. Ser24-phosphorylated Dab2 was mainly found in the cellular membrane fraction as shown by immunofluorescene staining analysis (Fig. 3b). These data indicate that Ser24-phosphorylated Dab2 is primarily found in the membrane fraction.

Thrombin-stimulated human platelets were subject to immunoprecipitation using the anti-pDab2 (Ser723) antibody for elucidating whether or not phosphorylation of Ser723 and Ser24 occurred in the same Dab2 molecule. Ser723- but not Ser24-phosphorylated Dab2 was found in the immunoprecipitated platelet lysates (Fig. 3c). These data indicate that Ser24 and Ser723 phosphorylations are mutually exclusive.

\section{Ser24-phosphorylated Dab2 underlies integrin outside-in signaling}

RGD-containing peptides inhibit fibrinogen binding consequently suppress platelet aggregation and outside-in signaling [38]. Human platelets were treated with different concentrations of the RGDS peptide prior to treatment with different types of agonists for determining whether or not Dab2-Ser24 phosphorylation is associated with integrin $\alpha \operatorname{Ilb} \beta 3$ inside-out or outside-in signaling. The RGDS peptide suppressed agonist-stimulated platelet aggregation (Fig. 4a), Dab2-Ser24 phosphorylation and protein degradation (Fig. 4b). Dab2-Ser723 phosphorylation which associates with integrin inside-out signaling [20] was unaffected (Fig. 4b). These data indicate that blocking of integrin outside-in signaling suppresses Dab2-Ser24 phosphorylation.

$\mathrm{PKC} \beta$ is the protein kinase for Ser 24 and is the PKC isoform that mainly mediates integrin outside-in signaling in platelets [39]. Human platelets were pre-treated with the PKC $\beta$-specific inhibitor, LY333531, [40] followed by thrombin stimulation for demonstrating that Dab2-Ser24 phosphorylation is involved in integrin outside-in signaling. Pretreatment of human platelets with LY333531 suppressed thrombin-stimulated platelet aggregation (Fig. 4c), Dab2-Ser24 phosphorylation and protein degradation (Fig. 4d) in a dose-dependent manner. Significant inhibition of Ser24 phosphorylation was observed when platelets were treated with LY333531 at $10 \mu \mathrm{M}(\mathrm{p}<0.01)$ and $50 \mu \mathrm{M}(\mathrm{p}<0.001)$, respectively. Dab2-Ser723 phosphorylation was unaffected (Fig. 4d, 4e). These data indicate that blocking PKC $\beta$ affects Dab2 phosphorylation in Ser24 and presumably this affects integrin outside-in signaling.

\footnotetext{
(See figure on next page.)

Fig. 1 Ser24 phosphorylation and proteolytic cleavage of Dab2 during agonist-induced human platelet activation. a The Dab2 Ser24 phospho-peptide (P-pep) but not the non-phospho-peptide (NP-pep) was recognized by a dot blot assay using the anti-p-Dab2 (S24) antibody. b 293T cells were transfected with HA-Dab2 (S24) or HA-Dab2-S24A (S24A) plasmids then stimulated with ethanol (E) or TPA (T, $1 \mu \mathrm{g} / \mathrm{ml}$ ) for 30 min. Lysates of 293 T cells were analyzed by Western blotting using the indicated antibodies. $\mathbf{c}$, $\mathbf{d}$ Human washed platelets were treated with the indicated concentrations of TPA under the thermomixer assay condition. Lysates of human platelets were analyzed by Western blotting using the indicated antibodies (panel c) or the anti-p-Dab2 (S24) antibody which has been pre-incubated with $\mathrm{H}_{2} \mathrm{O}$ (Control), P-pep or NP-pep as described in the peptide competition assays (panel d). e, $\mathbf{f}$ Human washed platelets were stimulated with the indicated concentrations of agonists and platelet aggregation was recorded by a platelet aggregometer (Chrono-Log). After $10 \mathrm{~min}$, human washed platelets were lysed and the platelet lysates were collected for Western blotting using the indicated antibodies. The proteolytic cleavage products of Dab2 were marked as *. $\mathbf{g}$, $\mathbf{h}$ Human washed platelets were pretreated with the indicated concentrations of MG-132 at RT for 30 min and then stimulated with TPA (25 ng/ml) and platelet aggregation was recorded by a platelet aggregometer (Chrono-Log). After $10 \mathrm{~min}$, human washed platelets were lysed and the platelet lysates were collected for Western blotting using the indicated antibodies. Arrows indicate the addition of TPA (panel g). The proteolytic cleavage products of Dab2 were marked as * (panel h). i The level of Dab2 Ser24 phosphorylation was quantified by ImageJ software and normalized by the expression of $\beta$-actin. The level of Dab2 Ser24 phosphorylation in the resting platelet lysate was arbitrarily set as 1 . The data are presented as the mean \pm SEM of $3-4$ independent experiments. ${ }^{*} p<0.05 ;{ }^{* *} p<0.01$
} 
a

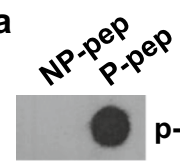

p-Dab2 (S24)

C

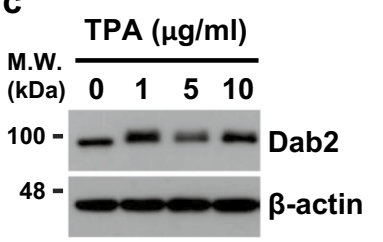

e

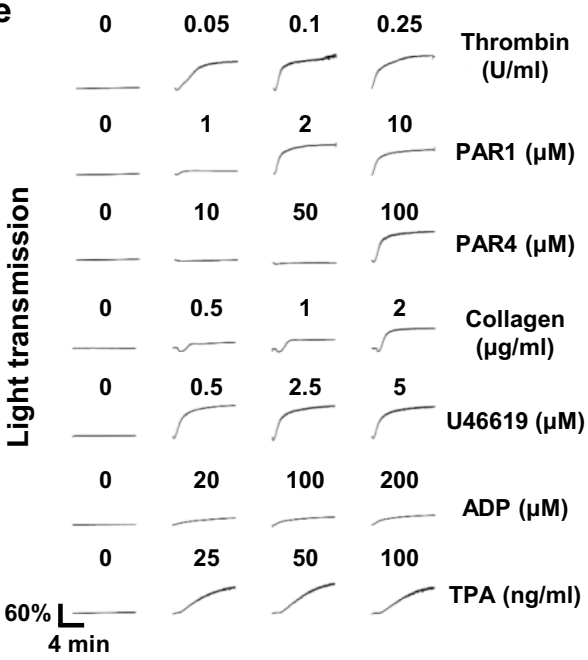

b

(kDa) E T E T

$135=$

100-

$63-$

48 -

35 -

$25-$

$100-$
$75-$

$75-$
$48-$

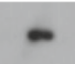

$4 \mathrm{~m}$
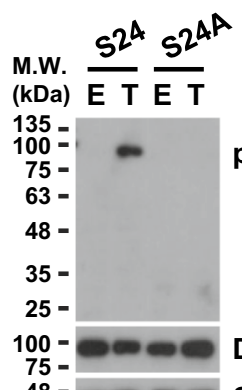

p-Dab2 (S24)

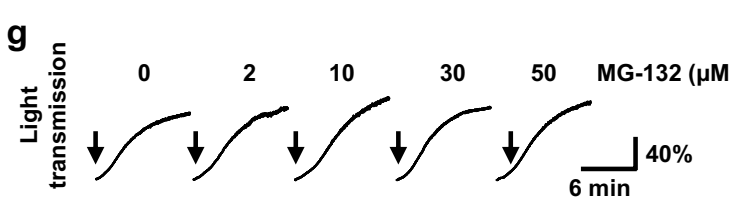

i

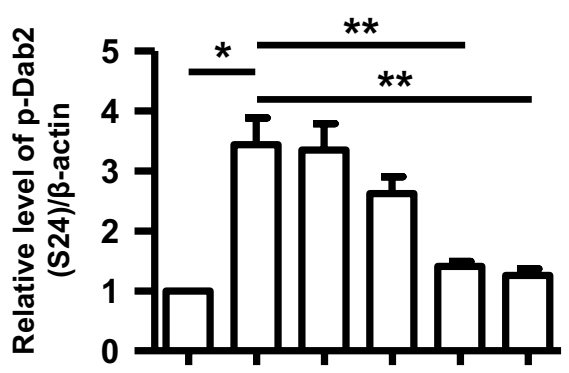

TPA (25 ng/ml)

MG-132 ( $\mu \mathrm{M})$
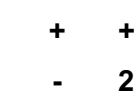

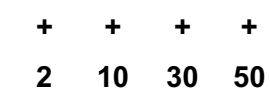

$\underset{\substack{\text { M.w. } \\ \text { (kDa) }}}{\text { Control }} \frac{\text { NP-PeP }}{E T} \frac{\text { P-PeP }}{E T}$

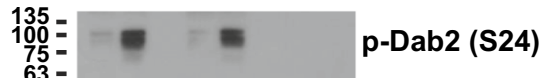

48 -

$35-$

25 -

$135=---\infty$
$75=-D a b 2$

$48--\infty-\infty-\infty$-actin

f

f Thrombin PAR1 PAR4

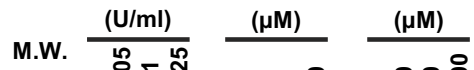

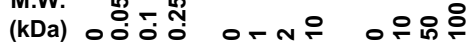

$100-==-\quad==p-D a b 2$ (S24)

$135=$

$100=$

$63-$

48 -

$35---7$

48 - - - - - - - - $\beta$-actin

Collagen U46619 ADP TPA

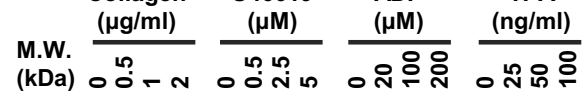

100 - - - - . - - = = - p-Dab2 (S24)

$135=$
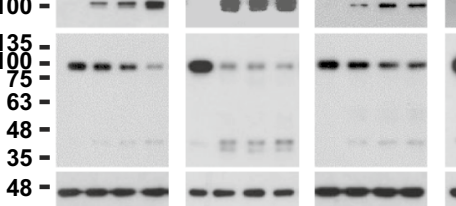

- - Dab2

$* n+*$ *

-0- $\beta$-actin

h M.W. - + + + + + TPA $(25 \mathrm{ng} / \mathrm{ml})$

$(\mathrm{kDa}) \quad-\quad-\quad 2 \quad 10 \quad 30 \quad 50 \quad \mathrm{MG}-132(\mu \mathrm{M})$

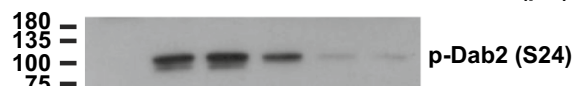

$100=\quad-\infty-\quad$ p-Dab2 (S24)

$63-$

$48-$

35 -

$100-\quad--\infty-\infty$ p-Dab2 (S723)

$180=$

$135=$

$100-\infty-m-\infty$ Dab2

75 -

63 -

48 -

$35-$

$48-\infty \omega \infty \omega \infty \operatorname{\beta actin}$
Manganese chloride $\left(\mathrm{MnCl}_{2}\right)$ or fibrinogen alone did not result in a significant increase $(p=0.27$ and $\mathrm{p}=0.77$, respectively) in Ser24 phosphorylation (Fig. 5a, $5 \mathrm{~b})$ comparing to no treatment group. Combined treatment of platelets with $\mathrm{MnCl}_{2}$ and fibrinogen increased
Dab2-Ser24 but not -Ser723 phosphorylation. The increase in Dab2-Ser24 phosphorylation was diminished when platelets were pre-incubated with the RGDS peptide (Fig. 5a, b). Outside-in signaling is activated directly by plating platelets on fibrinogen-coated slides. 

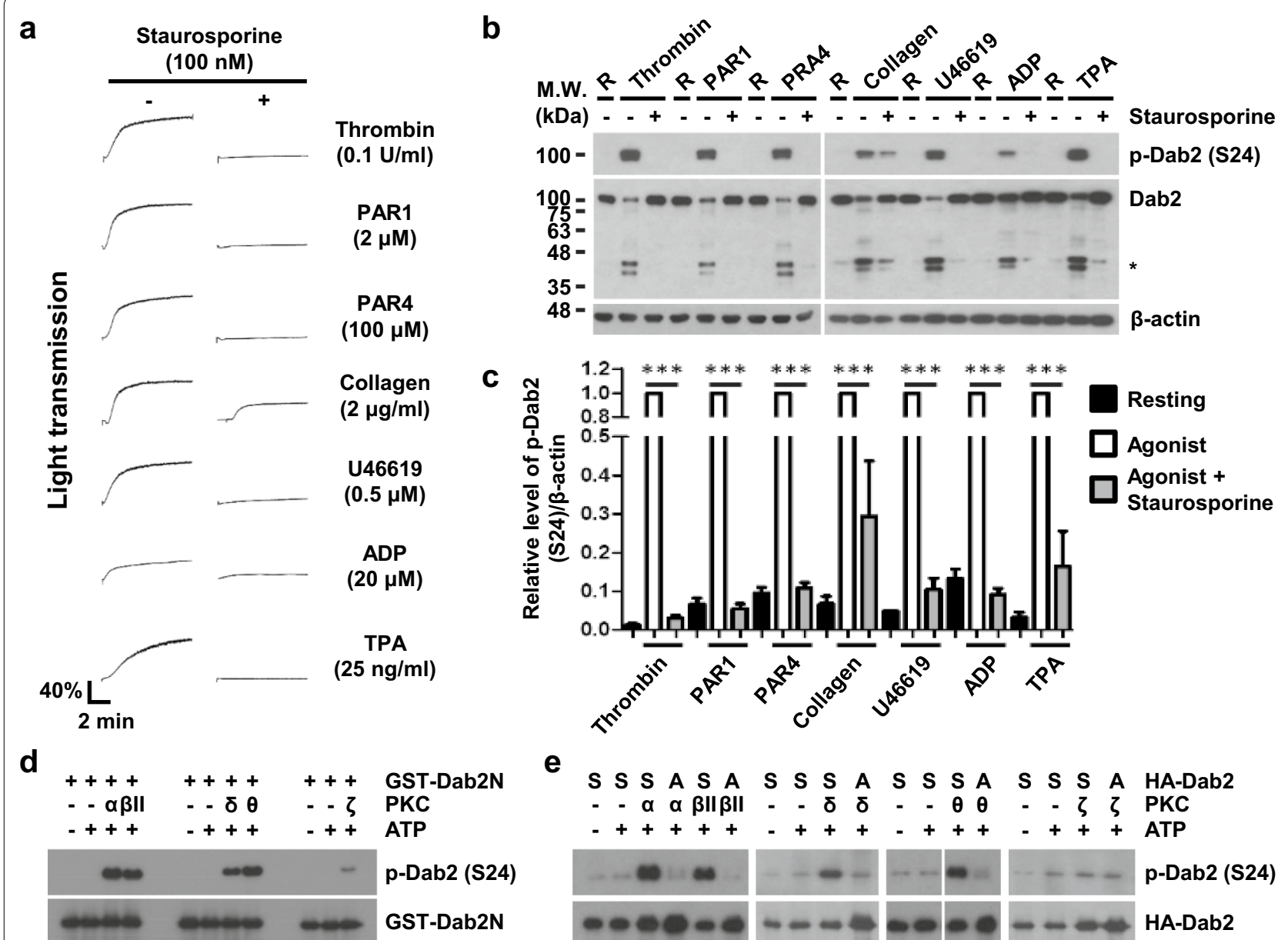

Fig. 2 PKC isoforms are responsible for the phosphorylation of Dab2-Ser24. a-c Human washed platelets were pretreated with staurosporine $(100 \mathrm{nM})$ for $5 \mathrm{~min}$ and then stimulated with the indicated concentrations of the agonists. Platelet aggregation was recorded by using a platelet aggregometer (Chrono-Log) (panel a). After 10 min, human washed platelets were lysed and the platelet lysates were collected for Western blotting using the anti-Dab2 (p96) and anti-p-Dab2 (S24) antibodies. The proteolytic cleavage products of Dab2 were marked as *. The expression of $\beta$-actin was used as a control of equal protein loading. $R$, resting platelets (panel b). The level of Dab2-Ser24 phosphorylation was quantified by ImageJ software and normalized by the expression of $\beta$-actin. The level of Dab2-Ser24 phosphorylation in agonist-stimulated platelet lysates was arbitrarily set as 1. The data are presented as the mean \pm SEM of 4 independent experiments. ${ }^{* *} p<0.001$ (panel c). d GST-Dab2N (1 234 amino acids) recombinant protein was used as the substrate for the in vitro protein kinase assay using the indicated PKC isoforms. The level of Dab2-Ser24 phosphorylation was analyzed by Western blotting using the anti-p-Dab2 (S24) antibody. The expression of GST-Dab2N recombinant protein was used for the control of equal protein loading. e HA-Dab2 (S) protein or HA-Dab2-S24A (A) protein from the lysates of 293T cells transfected with HA-Dab2 or HA-Dab2-S24A expression plasmids was enriched by immunoprecipitation using the anti-HA antibody. The immunoprecipitated proteins were used as the substrates for the in vitro protein kinase assay using the indicated PKC isoforms. The level of Dab2-Ser24 phosphorylation was determined by Western blotting using the anti-p-Dab2 (S24) antibody. The expression of HA-Dab2 or HA-Dab2-S24A was used for the control of equal protein loading

Spreading of human platelets on immobilized fibrinogen resulted in a time-dependent phosphorylation of integrin $\beta 3$ Tyr773 (Fig. 5c), a marker for integrin $\alpha \operatorname{IIb} \beta 3$ activation by outside-in signaling [41]. Integrin $\beta 3$ expression was not altered as revealed by the antibody (t-integrin $\beta 3)$ which recognized integrin $\beta 3$ protein. Dab2-Ser24 phosphorylation was also observed in the human platelets spreading on immobilized fibrinogen (Fig. 5c). These data indicate that the activation of integrin outside-in signaling is responsible for Dab2 Ser24 phosphorylation.

\section{Dab2-Ser24 phosphorylation mediated by the Src-PKC signaling axis and PLD1 activation regulates platelet spreading on fibrinogen}

Integrin $\alpha \operatorname{IIb} \beta 3$ outside-in signaling activates Src and PKC signaling causing granule secretion, TXA2 synthesis and platelet spreading $[39,42]$. PLD1 is also involved 


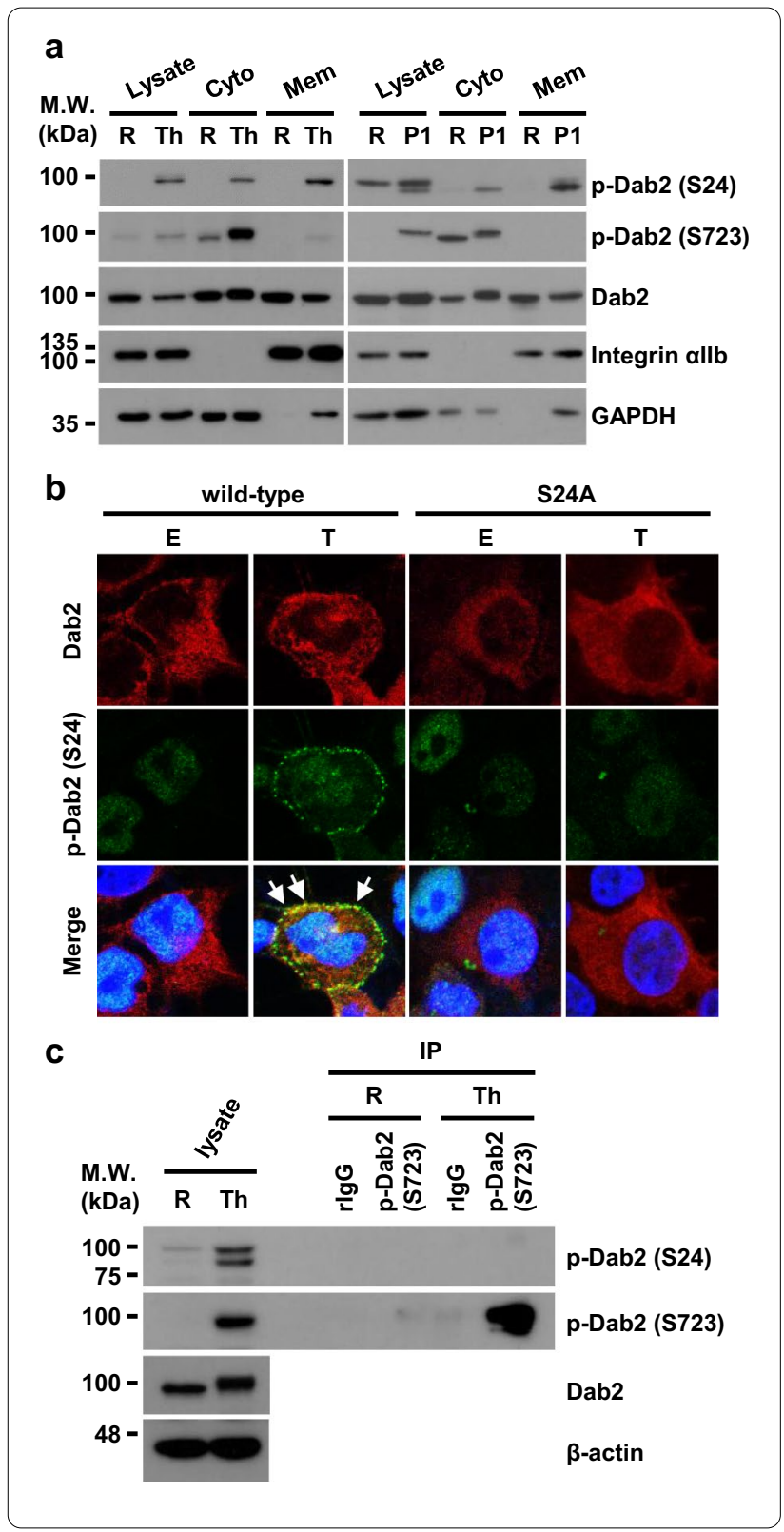

in outside-in signaling of integrin $\alpha \operatorname{IIb} \beta 3$ by supporting platelet adhesion, spreading and plug formation, thus stabilizing thrombus formation [43]. Spreading of human platelets on immobilized fibrinogen activated outside-in signaling and caused Src, PKC and PLD1 activation (Fig. 5 d). Human platelets were pre-treated with the indicated inhibitors to define the upstream signaling involved in the regulation of Dab2-Ser24 phosphorylation. Fibrinogen-induced Dab2 phosphorylation at Ser24 was inhibited by pre-treatment of the platelets with staurosporine (Stau, a PKC inhibitor), PP2 (a Src inhibitor) or VU0155069 (VU1, a PLD1 inhibitor) compared to the
Fig. 3 Ser24-phosphorylated Dab2 is mainly distributed in the membrane fraction of platelets. a Cytosolic (Cyto) and membrane (Mem) proteins were isolated from the resting (R) and thrombin (Th, $1 \mathrm{U} / \mathrm{ml}$ )- (left panel) or PAR1 peptide (P1, $10 \mu \mathrm{M}$ )- (right panel) stimulated human platelet lysates using the Mem-PER Plus Membrane Protein Extraction Kit protocol. The proteins were subject to Western blotting using the indicated antibodies. GAPDH and integrin allb was used as the marker for the cytosolic and membrane fractions, respectively. Representative data of 2-3 independent experiments are shown. b 293T cells were transfected with HA-Dab2 (wild-type) or HA-Dab2-S24A (S24A) expression plasmids and then stimulated with ethanol (E) or TPA (T, $1 \mu \mathrm{g} / \mathrm{ml})$ for $30 \mathrm{~min}$. Immunofluorescence staining was then performed using the mouse anti-Dab2 (red) and the rabbit anti-p-Dab2 (S24) (green) primary antibodies followed by the Alexa Fluor 546-conjugated anti-mouse IgG and the Alexa Fluor 488-conjugated anti-rabbit lgG secondary antibody. Nucleated cells were defined by positive fluorescent staining of Hoechst 33342 (blue). Arrows indicate the co-localization of Dab2 and p-Dab2 (S24). c The lysates (2 mg) from the resting (R) or thrombin-stimulated (Th, $1 \mathrm{U} / \mathrm{ml}$ ) human platelets were immunoprecipitated by the control rabbit lgG (rlgG) or anti-p-Dab2 (S723) antibody. The immunoprecipitated proteins (IP) were analyzed by Western blotting using the indicated antibodies. Representative data of 3 independent experiments are shown

platelets pre-incubated with the vehicle control DMSO, indicating that the integrin $\alpha \operatorname{IIb} \beta 3$ outside-in signaling activated the Src-PKC signaling axis and PLD1 activation leading to Dab2-Ser24 phosphorylation (Fig. 5e, f).

Dab2-Ser24 phosphorylation was inhibited by MG-132 in TPA-stimulated human platelets (Fig. 1h, i). The effect of MG-132 on platelet adhesion and spreading on fibrinogen was further examined to determine the role of Dab2-Ser24 phosphorylation in integrin $\alpha \operatorname{IIb} \beta 3$ outsidein signaling. Pre-incubation of platelets with MG-132 $(50 \mu \mathrm{M})$ had no effect on TPA-stimulated platelet adhesion but attenuated spreading on fibrinogen $(\mathrm{p}<0.01)$ (Fig. 6a, b). The number of platelet adhesion per field was $15 \pm 5,135 \pm 4$ and $113 \pm 7$ for the mock-, TPA- and MG-132 plus TPA-treated group, respectively. The number of platelet spreading on fibrinogen per field was $2 \pm 0$, $118 \pm 3$ and $74 \pm 7$ for the mock-, TPA-, and MG-132 plus TPA-treated group, respectively.

Arginine polypeptide, a kind of cell-penetrating peptides, is used to study platelet functions [20, 44, 45]. R11 was linked to the Dab2 peptide Ser24 (R11-S24) sequences which contain the Dab2-Ser24 phosphorylation site and its flanking sequences. A peptide with R11 and Dab2 S24A mutation (R11-S24A) was also synthesized (Table 2). These peptides were delivered into platelets to explore the effects of these peptides on Dab2-Ser24 phosphorylation and platelet spreading on fibrinogen. Platelet Dab2-Ser24 phosphorylation and platelet adhesion and spreading on BSA were limited. Dab2-Ser24 was phosphorylated and platelets adhered 


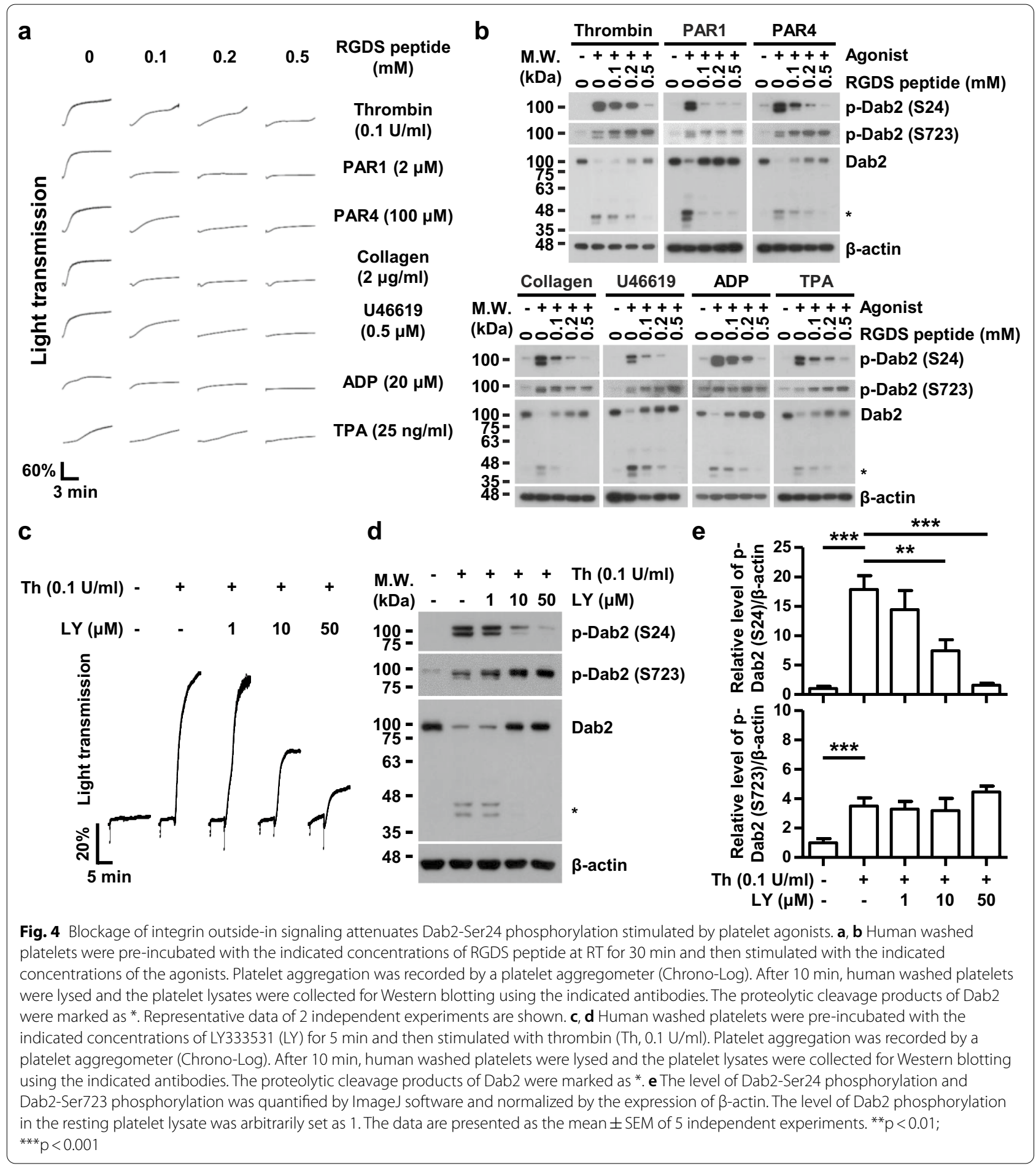

and spread well on fibrinogen when platelets were pretreated with R11. R11-S24 but not R11-S24A peptide attenuated both Dab2-Ser24 phosphorylation and platelet spreading on fibrinogen without any effect on platelet adhesion (Fig. 6c-e). The number of platelet adhesion on fibrinogen per field was $112 \pm 7,105 \pm 10$ and $98 \pm 8$ for R11-, R11-S24- and R11-S24A-treated group, respectively. The number of platelet spreading on fibrinogen per field was $76 \pm 5,36 \pm 6$ and $62 \pm 8$ for the R11-, R11-S24and R11-S24A-treated platelets, respectively (Fig. 6f). 


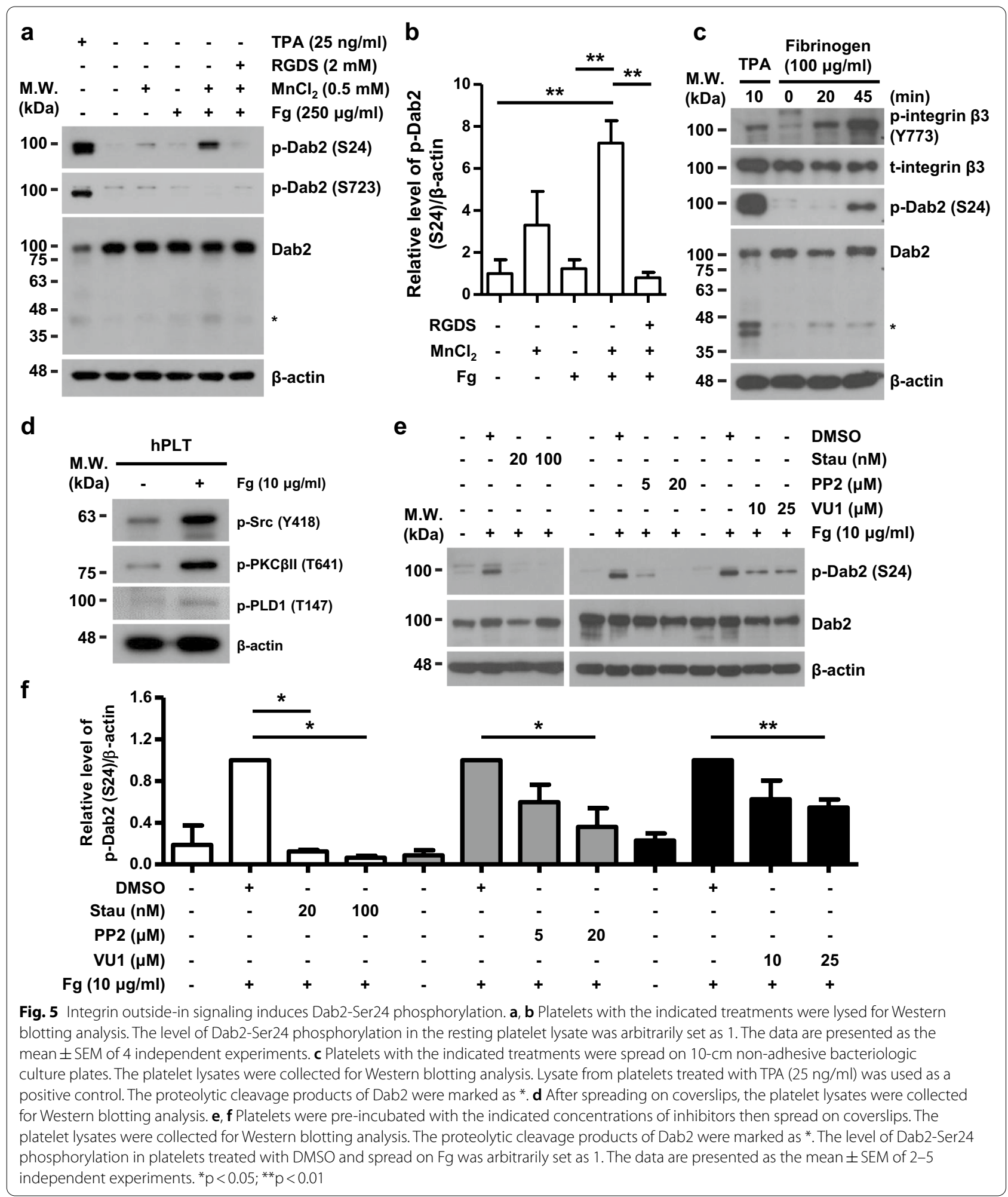

Consistent with these observations, pre-incubation of platelets with R11-S24 but not R11-S24A also attenuated thrombin-stimulated platelet spreading on fibrinogen when compared to the platelets pre-incubated with R11. No effect of R11-S24 was found on thrombin-stimulated platelet adhesion (Additional file 1: Fig. S1), fibrinogen 
a

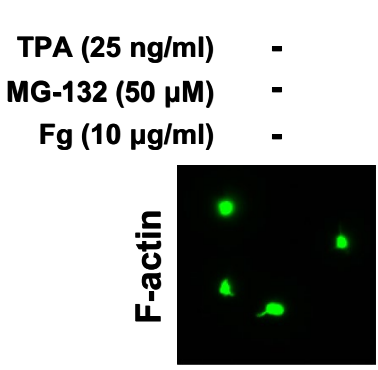

C

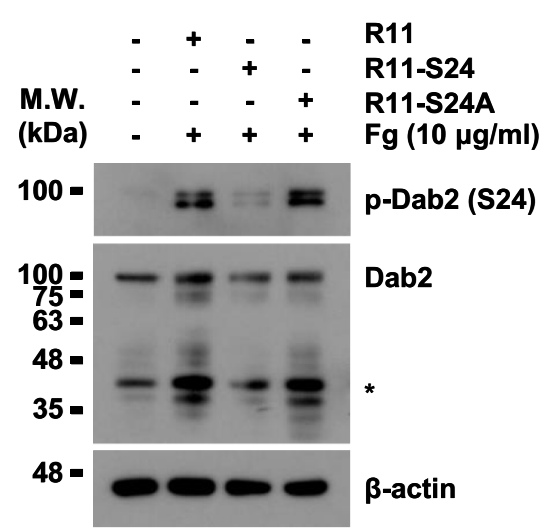

d

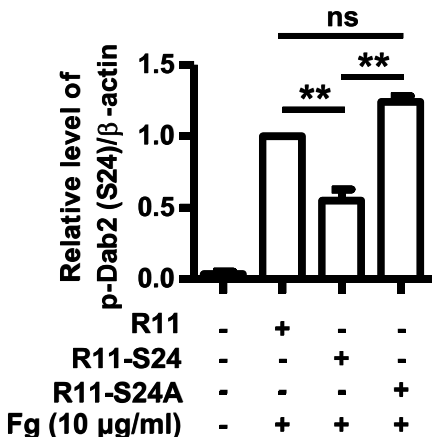

b

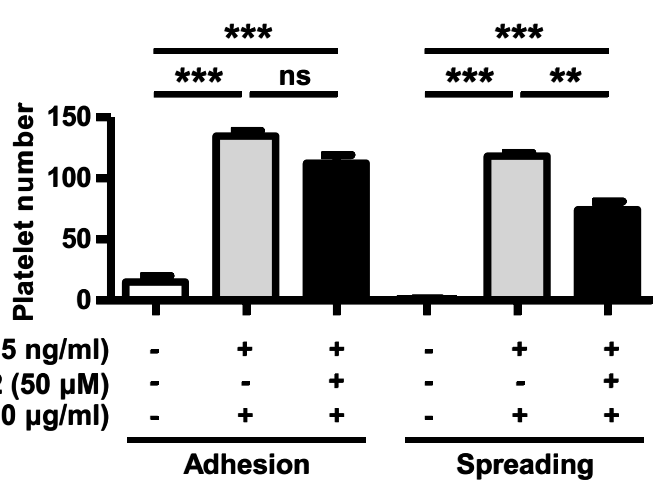

e

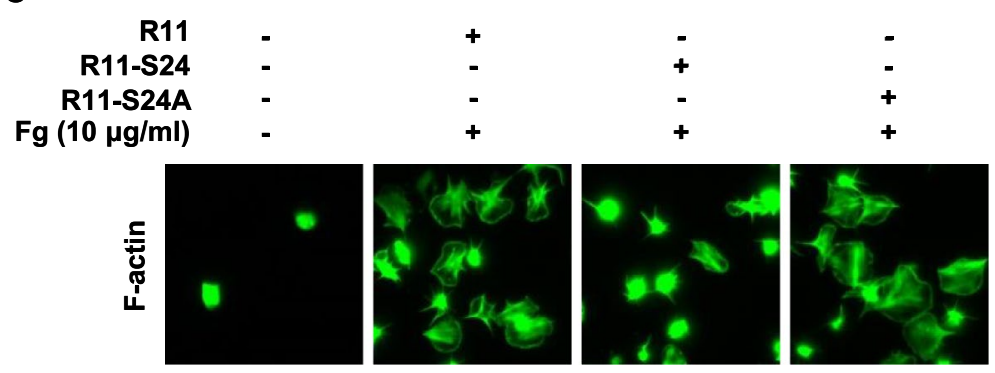

f

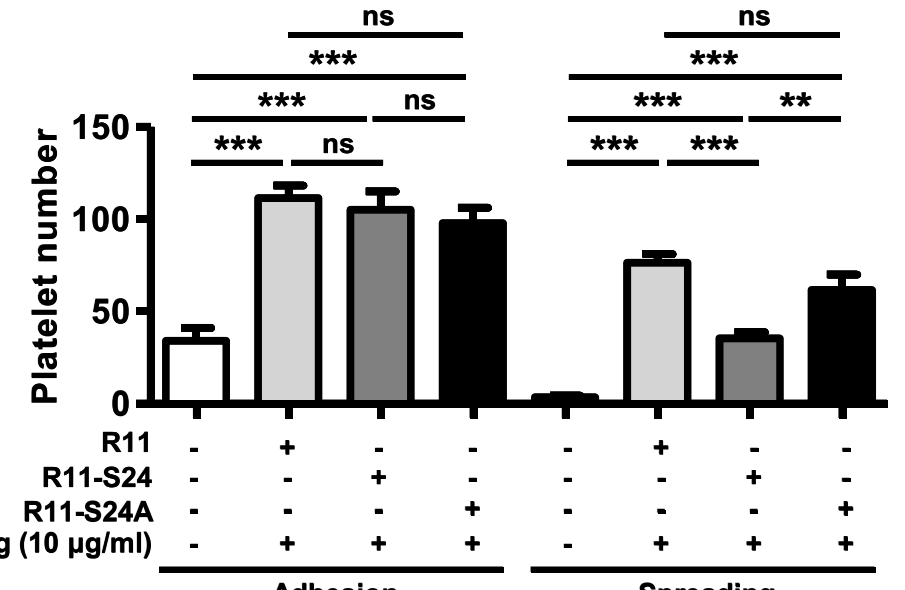

Adhesion

Spreading

Fig. 6 Dab2-Ser24 phosphorylation is involved in the regulation of cytoskeletal reorganization associated with outside-in signaling of integrin allb $\beta 3$. a, b Platelets with the indicated treatments were spread on coverslips. After spreading on coverslips, the platelets were fixed, permeabilized, stained for F-actin (green) and observed by phase contrast microscopy under a high power field (HPF) of 1,000 X magnification. The number of platelet adhesion/HPF and platelet spreading (area $>10 \mu \mathrm{m}^{2}$ )/HPF in each group is shown. The data are presented as the mean \pm SEM of 2 independent experiments with four assays. ns, no significance. $\mathbf{c}$, $\mathbf{d}$ After spreading on coverslips, the platelet lysates were collected for Western blotting analysis. The proteolytic cleavage products of Dab2 were marked as *. The level of Dab2-Ser24 phosphorylation in the platelets pretreated with R1 1 peptide was arbitrarily set as 1 . The data are presented as the mean \pm SEM of $2 \sim 6$ independent experiments. $\mathbf{e}, \mathbf{f}$ After spreading on coverslips, the platelets were fixed, permeabilized, stained for F-actin (green) and observed by phase contrast microscopy under a high power field (HPF) of 1,000 X magnification. The number of platelet adhesion/HPF and platelet spreading (area $\left.>10 \mu \mathrm{m}^{2}\right) / \mathrm{HPF}$ in each group is shown. The data are presented as the mean \pm SEM of $2 \sim 4$ independent experiments. ns, no significance. ${ }^{* *} p<0.01 ;{ }^{* * *} p<0.001$

binding, and platelet aggregation (Additional file 2: Fig. S2). These data indicate that Dab2-Ser24 phosphorylation is involved in the regulation of cytoskeletal reorganization associated with outside-in signaling of integrin $\alpha \operatorname{IIb} \beta 3$ but is not related to integrin $\alpha \operatorname{IIb} \beta 3$ inside-out signaling. 
Table 2 List of peptides that used in this study

\begin{tabular}{ll}
\hline Peptide name & Amino acid sequences \\
\hline Antigen peptides & \\
NP-pep & ${ }^{20}$ PKAPSKKEKKKGP ${ }^{32} \mathrm{C}$ \\
P-pep & ${ }^{20}$ PKAPpSKKEKKKGP ${ }^{32} \mathrm{C}$ \\
Cell-penetrating peptides & \\
R11 & RRRRRRRRRRR \\
R11-S24 & RRRRRRRRRRR ${ }^{19}$ APKAPSKKEKK ${ }^{29}$ \\
R11-S24A & RRRRRRRRRRR ${ }^{19}$ APKAPAKKEKK \\
\hline
\end{tabular}

pS phospho-serine

\section{Discussion}

$\alpha \operatorname{IIb} \beta 3$ is the dominant integrin on platelet membranes and it is essential for normal platelet function, hemostasis and thrombosis [1]. Integrin $\alpha \operatorname{IIb} \beta 3$ signaling is a complex process that is tightly and delicately regulated by several types of proteins, such as the transmembrane proteins, adaptor molecules, kinases, phosphatases and the Rhofamily small GTPases. In addition to its phosphorylation at Ser723 [20], Dab2 is phosphorylated at Ser24 by PKC when platelets are activated by agonists. Ser24-phosphorylated Dab2 is found mainly in the platelet membrane. It sustained integrin $\alpha \mathrm{IIb} \beta 3$ outside-in signaling and is associated with Dab2 protein degradation.

Considerable effort is still needed to fully explore how integrin $\alpha \operatorname{IIb} \beta 3$ interacts with its regulatory proteins, and how its regulatory proteins interact with one another in space and time. The PTB domain of Dab2 interacts with the non-phosphorylated NPXY motifs located at the amino acids 744-747 and 756759 of the integrin $\beta 3$ cytoplasmic tail $[11,18]$. Dab2 when released from activated platelets interacts with the fibrinogen binding site of integrin $\alpha \mathrm{IIb}$ and the phospholipid sulfatide on the outer surface of the platelet membrane [19, 22-24]. The balance of Dab2 between sulfatide- and integrin receptor-bound states is involved in the control of the extent of the clotting response [22]. The involvement of Dab2 in integrin $\alpha \mathrm{IIb} \beta 3$ signaling is complicated by the change in Dab2 phosphorylation during platelet activation. This and our previous study [20] defined Dab2 phosphorylation at Ser24 and Ser723 in human platelets, respectively. Although the phosphorylaton of these two amino acids occurred during agonist-stimulated platelet activation, they have unique characteristics and play distinct roles in integrin signaling. First, Ser723 and Ser24 phosphorylation of Dab2 was induced by integrin inside-out and outside-in signaling, respectively. This is supported by the finding that blockage of integrin outside-in signaling with the RGD peptide inhibited agonist-induced Ser24 but not Ser723 phosphorylation. Ser24 but not
Ser723 phosphorylation was induced by plating platelets on fibrinogen or treating platelets with fibrinogen and $\mathrm{MnCl}_{2}$. Both approaches have been shown to directly initiate integrin outside-in signaling [39]. Second, Ser723- and Ser24-phosphorylated Dab2 have distinct functions in integrin inside-out and outside-in signaling. Ser723 phosphorylation of Dab2 underlies thrombin-stimulated inside-out signaling of integrin and, by regulating the interaction between Dab2 and CIN85, provides an alternative pathway in the control of ADP/dense granule release, fibrinogen binding, platelet aggregation, and integrin $\alpha \operatorname{IIb} \beta 3$ activation [20]. Ser24 phosphorylation of Dab2 was mediated by outside-in signaling of integrin and controlled platelet spreading on fibrinogen, as evidenced by the fact that the R11-S24 peptide inhibited Dab2 Ser24 phosphorylation and platelet spreading on fibrinogen. These studies thereby suggest that Dab2 plays a dual role in inside-out and outside-in signaling of integrin $\alpha \operatorname{IIb} \beta 3$ through multiple mechanisms including the Dab2-integrin $\alpha \operatorname{IIb} \beta 3$ interaction and phosphorylation at specific amino acid residues of Dab2. This study adds to the list of adaptor proteins, in addition to talin [5], that have a dual function in the regulation of inside-out and outside-in signaling of integrin $\alpha \operatorname{IIb} \beta 3$.

Several findings in the current study may explain how Dab2 elicits distinct functions in bidirectional integrin signaling. Dab2-Ser24 phosphorylation appears to correlate with the degree of platelet aggregation stimulated by the agonists. Attenuation of Dab2-Ser24 phosphorylation but not platelet aggregation by the proteasome inhibitor MG-132 indicates that Dab2-Ser24 phosphorylation is not related to integrin inside-out signaling and platelet aggregation. The mechanism for dephosphorylation of Dab2-Ser24 may attribute to the increase in phosphatase activity by MG-132. As described in previous studies, MG-132 promotes protein phosphatase $2 \mathrm{~A}$ to dephosphorylate endothelial nitric oxide synthase that governs the nitric oxide-dependent signaling pathways in vascular endothelial cells [46]. It also activates dual specificity phosphatases to systemically perturb the intracellular phosphoproteome and the transition of kinase cascade signaling [47]. Hence, MG-132 may potentially regulate integrin signaling via its regulation of Dab2-Ser24 phosphorylation.

Dab2-Ser24 phosphorylation was not detected in the protein lysate immunoprecipitated by the anti-Ser723Dab2 antibody, indicating that a single Dab2 protein is phosphorylated exclusively either at Ser24 or Ser723. Ser24- and Ser723-phosphorylated Dab2 was found mainly in the platelet membrane and the cytosolic fraction, respectively. There are at least two pools of Dab2 proteins within the agonist-stimulated platelets. 
Ser723-phosphorylated Dab2 found in the cytosolic fraction of platelets was involved in integrin inside-out signaling. Dab2-Ser723 phosphorylation causes the dissociation of Dab2-CIN85 complex and regulates $\alpha \operatorname{IIb} \beta 3$ activation and ADP release leading to an increase in fibrinogen binding and platelet aggregation in thrombin-stimulated platelets [20]. Ser24-phosphorylated Dab2 found in the membrane fraction of platelet mediated integrin outside-in signaling. Mutually exclusive phosphorylation of specific amino acid residues has been employed by other proteins in generating specificity and pleiotropy in biological systems $[48,49]$. The mechanisms for mutually exclusive phosphorylation of Ser24 and Ser723 are still not clear. Phosphorylation at either Ser24 or Ser723 may cause spatial hindrance that exclude the access of protein kinase to the other phosphorylation site. It is also likely that the spatial association of Dab2 and specific PKC isoform(s) within a specific compartment favors one of the phosphorylation sites over the other and determines the specificity of PKC isoforms in the phosphorylation of Dab2 at Ser24 or Ser723. Mutually exclusive phosphorylation of Dab2 may thereby play an important role in generating specificity and pleiotropy of integrin signaling.

The signaling axis leading to Dab2-Ser24 phosphorylation was investigated in this study. PKC isoforms in integrin signaling play a specific role in platelet activation [50]. PKC $\alpha$ regulates dense granule secretion and in parallel reduces collagen-related peptide-induced $\alpha \operatorname{IIb} \beta 3$ activation and platelet aggregation in response to submaximal agonist concentrations [51]. PKC $\beta$ is recruited to $\alpha \operatorname{IIb} \beta 3$ via RACK1 and is involved in the regulation of platelet spreading on fibrinogen or integrin activation by $\mathrm{Mn}^{2+}$ and soluble fibrinogen [39]. PKC $\delta$ plays an essential role in platelet signaling, integrin $\alpha \operatorname{IIb} \beta 3$ activation, and TXA2 release [52]. PKCO is required for hemostasis and the positive regulation of thrombin-induced platelet aggregation and $\alpha$-granule secretion $[35,53]$. PKC $\eta$ positively regulates agonist-induced thromboxane generation with no effect on platelet aggregation [54]. Although most PKC isoforms serve as the protein kinases for Dab2Ser24 in the in vitro protein kinase assays, PKC isoforms usually elicit substrate specificity in vivo. Consistent with the role of $\mathrm{PKC} \beta$ and Dab2-Ser24 phosphorylation in outside-in signaling of integrin, Ser24 phosphorylation of Dab2 in human platelets was inhibited by pretreatment of the platelets with a PKC $\beta$ inhibitor. Together with the inhibition of Ser24 phosphorylation by the Src inhibitor (PP2) and the PKC inhibitor (staurosporine), the signaling axis of integrin-Src-PKC $\beta$-Dab2 may mediate Dab2-Ser24 phosphorylation associated with integrin outside-in signaling. On the other hand, Dab2Ser24 phosphorylation was inhibited by pretreatment of platelets with the PLD1 inhibitor (VU0155069). PKC is downstream of PLD activation and signaling $[55,56]$ and PLD mainly functions in the cleavage of phospholipids to produce phosphatidic acid which metabolize to lysophosphatidic acid or to the PKC activator diacylglycerol [57]. Instead of direct regulation of Dab2-Ser24 phosphorylation, PLD most likely plays a role in activating PKC and provides a positive feedback loop to stimulate Dab2-Ser24 phosphorylation.

The molecular details regarding how Dab2-Ser24 phosphorylation regulates platelet spreading on fibrinogen and integrin outside-in signaling remains to be fully explored. Based on the data of this study, Dab2 may act as a negative regulator of outside-in signaling and form molecular complexes with integrin-associated proteins and/or phospholipids. Dab2-Ser24 phosphorylation may fine-tune the interaction between Dab2 and the integrin-associated signaling molecules, release its suppressive function in outside-in signaling and cause platelet spreading on fibrinogen. To assure full activation of outside-in signaling, Dab2 thereby undergoes degradation after phosphorylation. We noted that these findings are not in accord with our previous study using TPA-mediated megakaryocytic differentiation of $\mathrm{K} 562$ cells as the model system which revealed that Dab2-Ser24 phosphorylation acts as a negative regulator in $\alpha \operatorname{IIb} \beta 3$ inside-out signaling [18]. The different functions of Dab2-Ser24 phosphorylation in integrin signaling may be attributed to the use of different experimental approaches and model systems. The involvement of Dab2-Ser24 phosphorylation in integrin inside-out signaling is mainly based on ectopic expression of wild type and S24A-mutated Dab2 in the K562 cells. Wild type Dab2 but not the S24A mutant associates with membrane and interacts with integrin $\beta 3$ leading to a decrease in $\alpha \operatorname{IIb} \beta 3$ activation and $\alpha I I b \beta 3$-mediated fibrinogen adhesion (inside-out signaling) [18]. In order to transform K562 cells into megakaryocyte-like cells, most of these analyses were performed with long term treatment of TPA $(48 \mathrm{~h})$. In the current study, the functional role of Dab2 in outside-in signaling was directly addressed using platelet as the model system with short term treatment of agonists (10-45 min). With the different cellular content of the model systems, the integrin-related signaling proteins may have distinct components with various spatial and temporal regulation and assembly of protein complexes, and enzymatic activity (such as PKC) in platelets and the megakaryocytic differentiated K562 cells. Ser24-phosphorylated Dab2 may thereby interact with different subsets of integrin signaling proteins and elicit different functional roles in integrin signaling. Moreover, the controversial results may due to different combinations of phosphorylation of various additional sites in platelets and K562 cells. In this 


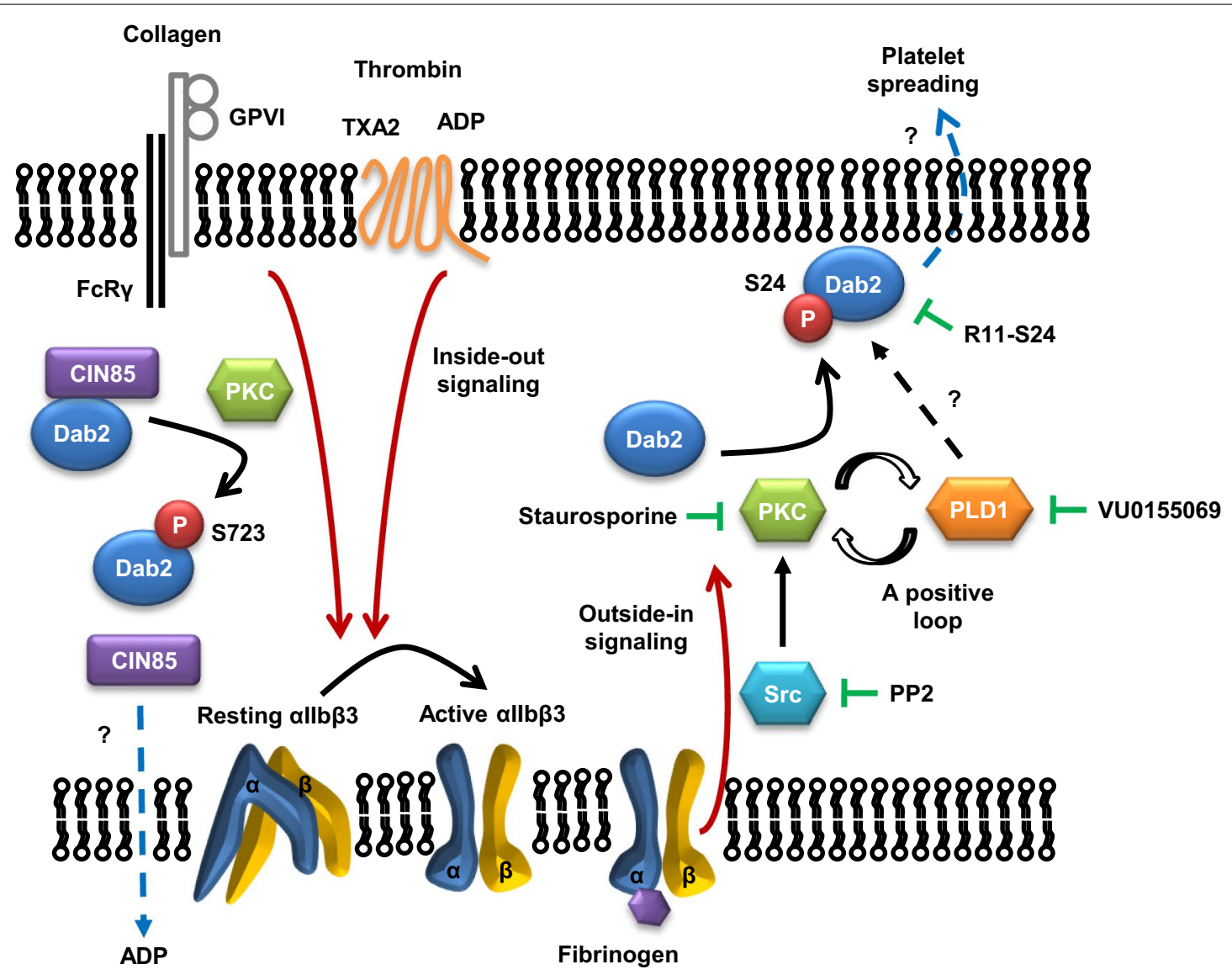

Fig. 7 Proposed model for the dual role of Dab2 phosphorylations in platelet activation. Two pools of Dab2 are present in human platelets. PKC-mediated Dab2 Ser723 phosphorylation mainly distributed in the cytosolic fraction causes the dissociation of Dab2-CIN85 protein complex upon agonist-stimulated integrin inside-out signaling. The molecular consequences for the dissociation of Dab2-CIN85 protein complex is related to ADP release, integrin allb $\beta 3$ activation, fibrinogen binding and platelet aggregation. Activation of the Src-PKC signaling axis and PLD underlying integrin outside-in signaling causes Dab2-Ser24 phosphorylation, which is mainly distributed in the membrane fraction and subsequently regulates platelet spreading on fibrinogen. PP2 (a Src inhibitor), staurosporine (a PKC inhibitor), VU0155069 (a PLD1 inhibitor) and R11-S24 peptide suppress Dab2-Ser24 phosphorylation

regard, Dab2 phosphorylation at the amino acid residues of Ser224, Ser249, Ser394, and Ser401 has been reported in agonist-stimulated platelet lysates [20,30]. We could not rule out the contributions of other phosphorylation or molecular events that together with Dab2-Ser24 phosphorylation in integrin signaling. Generation of an antibody specific to the phosphorylated amino acid residues and further investigation of the underlying functions of these phosphorylation events are required.

In addition to providing new insights into the function of Dab2-Ser24 phosphorylation in integrin $\alpha \operatorname{IIb} \beta 3$ outside-in signaling, a Dab2-Ser24 specific antibody and a R11-Dab2 peptide with inhibitory activity on Ser24 phosphorylation proved useful for functional studies of Dab2-Ser24 phosphorylation in human platelets. Dab2 phosphorylation is involved in endocytosis, cell cycle progression, and cell proliferation [18, 25-34].
The Dab2-Ser24 phospho-specific antibody and the R11-Dab2 cell penetrating peptide are valuable tools for exploring the functional role of Dab2-Ser24 phosphorylation in other cellular processes.

\section{Conclusions}

Based on the findings of the current and previous studies $[20,58]$, a model for the function and regulation of Dab2 phosphorylation in platelet signaling is proposed (Fig. 7). Distinct pools of Ser723- and Ser24-phosphorylated Dab2 are present in agonist-stimulated human platelets. Ser723 phosphorylation induced by platelet agonists regulates Dab2-CIN85 protein complexes and transmits integrin inside-out signaling, leading to activation of integrin $\alpha \operatorname{IIb} \beta 3$ [20]. Novel evidence presented in the current study shows that Dab2-Ser24 phosphorylation induced by the integrin-Src-PKC and PLD1 signaling 
axis mediates integrin $\alpha \mathrm{IIb} \beta 3$ outside-in signaling and plays a pivotal role in platelet spreading on fibrinogen. This study sheds light on the molecular basis of integrin $\alpha \operatorname{IIb} \beta 3$ signaling in human platelets. Better understanding of integrin $\alpha \operatorname{IIb} \beta 3$ signaling could provide greater insight into the mechanism of thrombus formation, leading to the development of new therapeutic agents for counteracting clot formation.

\section{Methods}

\section{Reagents}

Thrombin, fibrinogen and ADP were purchased from Calbiochem (Darmstadt, Germany). The collagen was purchased from Chrono-Log (Havertown, PA). Apyrase, TPA, $\mathrm{MnCl}_{2}$, anti-HA agarose, Freund's adjuvant complete and Freund's adjuvant incomplete were purchased from Sigma (St Louis, $\mathrm{MO})$. Prostaglandin $\mathrm{I}_{2}\left(\mathrm{PGI}_{2}\right)$ and U46619 were purchased from Cayman Chemical (Ann Arbor, MI). LY333531 was purchased from MedChemExpress (Monmouth Junction, NJ). The anti-Dab2 (p96) antibody was purchased from BD Biosciences (San Diego, CA). The anti- $\beta$-actin antibody was purchased from Novus Biological (Mill Valley, CA). The anti-p-integrin $\beta 3$ (Y773) antibody and Lipofectamine 2000 reagent were purchased from invitrogen (Carlsbad, CA). The anti-t-integrin $\beta 3$ (N20) antibody was purchased from Santa Cruz Biotechnologies (Santa Cruz, CA). The protein kinases were purchased from SignalChem (Richmond, BC). Acti-stain 488 phalloidin was purchased from Cytoskeleton inc. (Denver, CO). Amicon Ultra15 Centrifugal Filter Units (3 K) was purchased from Merck Millipore (Darmstadt, Germany). PAR1 peptide (SFLLRN-NH2, purity >95\%), PAR4 peptide (AYPGKFNH2, purity $>95 \%$ ), R11 peptide (RRRRRRRRRRR, purity > 95\%), R11-S24 peptide (RRRRRRRRRRR ${ }^{19}$ APKAPSKKEKK ${ }^{29}$, purity > 95\%), R11-S24A peptide (RRRRRR RRRRR ${ }^{19}$ APKAPAKKEKK ${ }^{29}$, purity > 95\%) and RGDS peptide were synthesized by Kelowna international Scientific inc. (Taiwan).

\section{Generation of the phospho-Ser24-specific anti-Dab2 antibody}

The synthetic peptide (antigen) corresponding to the amino acid residues 20-32 of human Dab2 (Table 2) was synthesized and conjugated with keyhole limpet hemocyanin by $2 \%$ glutaraldehye. The peptide $(1 \mathrm{mg} / \mathrm{mL})$ was mixed with $1 \mathrm{ml}$ Freund's adjuvant complete and was subcutaneously injected into the rabbit. After a second immunization, the blood was collected and the antibody was purified by using a two-step affinity column purification protocol and concentrated by Amicon Ultra-15 Centrifugal Filter Units (3 K).

\section{Dot blot assay}

The peptides $(20 \mathrm{nmol})$ were spotted onto the nitrocellulose membrane. The membrane was air-dried and blocked with $5 \%$ non-fat milk in $0.05 \%$ TBS-T (20 mM Tris- $\mathrm{HCl}, 150 \mathrm{mM} \mathrm{NaCl}, \mathrm{pH} 7.5$ and $0.05 \%$ Tween-20) for $30 \mathrm{~min}$ followed by protein detection as described in Western blot analysis.

\section{Western blot analysis}

Western blotting was performed as described previously $[20,59]$. Proteins were separated by SDS-PAGE under reducing condition, transferred to a polyvinylidene fluoride membrane and blocked with 5\% non-fat milk for $1 \mathrm{~h}$. The membrane was incubated with primary antibody at room temperature (RT) for $1.5 \mathrm{~h}$ followed by secondary antibody for $1 \mathrm{~h}$. Protein expression was detected by ECL-Plus reagents. The level of Dab2-Ser24 phosphorylation was quantified by ImageJ software and normalized by the expression of $\beta$-actin.

\section{Cell culture, transfection and immunoprecipitation}

The 293T cells were cultured in Dulbecco's modified eagle medium supplemented with $5 \%$ fetal bovine serum and were transfected with plasmid DNA using the Lipofectamine 2000 reagent as described previously [60]. For immunoprecipitation, $2 \mathrm{mg}$ of protein were incubated with $20 \mu \mathrm{l}$ of anti-HA agarose or $2 \mu \mathrm{g}$ of the indicated antibody at $4{ }^{\circ} \mathrm{C}$ for $2.5 \mathrm{~h}$. The protein complexes were washed five times with $1 \mathrm{X}$ lysis buffer and readied for the in vitro protein kinase assay.

\section{Peptide competition assay}

The peptide competition assay was performed using phosphorylated or non-phosphorylated peptides with a phospho-specific primary antibody, where an antibody concentration of $1 \mu \mathrm{g} / \mathrm{ml}$ and a 200-fold molar excess of peptide were used in a total reaction volume of $3 \mathrm{ml}$. Antibodies with peptides were incubated at room temperature for $30 \mathrm{~min}$ with gentle rocking. The immune complexes were removed by centrifugation at $4{ }^{\circ} \mathrm{C}$ and $13,200 \mathrm{rpm}$ for $15 \mathrm{~min}$. The supernatant was collected carefully. The pre-incubated antibodies in each sample were ready for use.

\section{Human washed platelets preparation}

Whole blood from healthy donors was mixed with sodium citrate $(3.15 \%)$ in the ratio of nine to one and was centrifuged at $200 \mathrm{~g}$ for $20 \mathrm{~min}$ to obtain platelet-richplasma (PRP). Platelets were then obtained by centrifugation of PRP at $980 \mathrm{~g}$ for $10 \mathrm{~min}$ in the presence of $\mathrm{PGI}_{2}$ $(0.3 \mu \mathrm{g} / \mathrm{ml})$. After washing twice with Tyrode's buffer [61] supplemented with $\mathrm{PGI}_{2}(0.3 \mu \mathrm{g} / \mathrm{ml})$ and apyrase $(0.02 \mathrm{U} /$ 
$\mathrm{ml}$ ), the washed platelets were resuspended in Tyrode's buffer.

\section{Platelet activation assay}

In thermomixer assay condition, $200 \mu \mathrm{l}$ of washed platelets $\left(3 \times 10^{8} / \mathrm{ml}\right)$ was added into an eppendorf tube and stimulated with the indicated agonists at $37{ }^{\circ} \mathrm{C}$ under stirring at $500 \mathrm{rpm}$ for $10 \mathrm{~min}$. For the aggregometer (Chrono-Log) assay, $500 \mu \mathrm{l}$ of washed platelets $(3 \times$ $10^{8} / \mathrm{ml}$ ) was added into a cuvette with a stirring bar and stimulated with the indicated agonists at $37{ }^{\circ} \mathrm{C}$ under stirring at $1000 \mathrm{rpm}$ for $10 \mathrm{~min}$. After the addition of $5 \times$ lysis buffer ( $50 \mathrm{mM}$ Tris $-\mathrm{HCl}(\mathrm{pH}$ 7.4), $500 \mathrm{mM} \mathrm{NaCl}$, $2.5 \mathrm{mM} \mathrm{CaCl}_{2}, 2.5 \mathrm{mM} \mathrm{MgCl}_{2}$, 5\% Triton X-100, $50 \mu \mathrm{g} /$ $\mathrm{ml}$ aprotinin, $50 \mu \mathrm{g} / \mathrm{ml}$ leupeptin, $5 \mathrm{mM}$ phenylmethylsulfonyl fluoride (PMSF), $1 \mathrm{mM}$ sodium orthovanadate, $50 \mathrm{mM}$ sodium fluoride, and $5 \mathrm{mM}$ EGTA), samples were collected for Western blotting.

\section{In vitro protein kinase assay}

HA-Dab2 or HA-Dab2-S24A was immunoprecipitated by the use of anti-HA agarose from 293T cells overexpressing the indicated Dab2 proteins. In vitro protein kinase assays were performed by incubating the immunoprecipitated proteins or the GST-Dab2N recombinant protein with the kinase buffer [28] in the presence of the indicated protein kinases at $30{ }^{\circ} \mathrm{C}$ for $30 \mathrm{~min}$. The assay was then terminated by adding $5 \times$ sample buffer.

\section{Subcellular fractionation of platelet lysates}

Subcellular fractionation of platelet lysates was performed according to the manufacturer's instruction of Mem-PER Plus Membrane Protein Extraction Kit (ThermoFisher). Platelets were obtained by centrifugation at $980 \mathrm{~g}$ for $10 \mathrm{~min}$ and lysed by $750 \mu \mathrm{l}$ Permeabilization Buffer at $4{ }^{\circ} \mathrm{C}$ rotated for $10 \mathrm{~min}$. Cytosolic proteins were collected by centrifugation at $16,000 \mathrm{~g}$ for $15 \mathrm{~min}$. The pellet was incubated with $500 \mu$ l of Solubilization Buffer at $4{ }^{\circ} \mathrm{C}$ rotated for $30 \mathrm{~min}$. Membrane-associated proteins were collected by centrifugation at $16,000 \mathrm{~g}$ for $15 \mathrm{~min}$.

\section{Immunofluorescence staining and F-actin staining}

Cells or adhered platelets were fixed with $4 \%$ paraformaldehyde at RT for $10 \mathrm{~min}$ and then washed twice with $1 \times$ PBS. Fixed cells were permeabilized with $1 \times$ PBS containing $0.1 \%$ Triton X-100 at RT for $10 \mathrm{~min}$ and then washed twice with $1 \times$ PBS. For immunofluorescence staining, cells were blocked with $3 \%$ bovine serum albumin (BSA) at RT for $30 \mathrm{~min}$ and then incubated with the mouse anti-Dab2 (p96) or the rabbit anti-p-Dab2 (S24) antibody at RT for $60 \mathrm{~min}$. After washing twice with $1 \times$ PBS, cells were incubated with the Alexa Fluor 546-conjugated anti-mouse IgG secondary antibody or Alexa Fluor 488-conjugated anti-rabbit IgG secondary antibody at RT for $40 \mathrm{~min}$. Nucleated cells were defined by positive fluorescent staining of Hoechst 33,342. For F-actin staining, platelets were stained with acti-stain 488 phalloidin $(100 \mathrm{nM})$ at RT for $30 \mathrm{~min}$ and then washed twice with $1 \times$ PBS. Stained cells on coverslips were mounted with Dako mounting medium and observed by microscopy.

\section{Fibrinogen-induced outside-in signaling assay}

The 10-cm non-adhesive bacteriologic culture plates were pre-coated with $100 \mu \mathrm{g} / \mathrm{mL}$ fibrinogen and kept at $4{ }^{\circ} \mathrm{C}$ overnight. After blocking with heat-denatured $\left(70{ }^{\circ} \mathrm{C}\right.$ for $1 \mathrm{~h}) 5 \% \mathrm{BSA}, 2 \mathrm{ml}$ of washed platelets $\left(3 \times 10^{8} / \mathrm{ml}\right)$ was added and incubated at $37{ }^{\circ} \mathrm{C}$ for the indicated period of time. For inhibitors and the R11 peptide (Table 2) assay, $24 \times 60 \mathrm{~mm}$ coverslips were pre-coated with $10 \mu \mathrm{g} / \mathrm{mL}$ fibrinogen and kept overnight at $4{ }^{\circ} \mathrm{C}$. After blocking with heat-denatured 5\% BSA, $2 \mathrm{ml}$ of the washed platelet (3 $\times 10^{8} / \mathrm{ml}$ ) was pre-treated with R11, R11-Dab2 peptide $(375 \mathrm{nM})$ or the indicated concentrations of the inhibitors at RT for $5 \mathrm{~min}$. The platelets were then added onto the coverslips and incubated at $37^{\circ} \mathrm{C}$ for $45 \mathrm{~min}$. Platelet adhesion and spreading on BSA-blocked coverslips was used as a control group in this assay. After rinsing twice with Tyrode's buffer, the reaction was stopped, and the lysates of the platelets adherent to fibrinogen were prepared by adding $1 \times$ lysis buffer.

\section{Fibrinogen binding assay}

Platelets were stimulated with indicated agonists and incubated with Alexa Fluor 488-conjugated fibrinogen $(10 \mu \mathrm{g} / \mathrm{ml})$ for $20 \mathrm{~min}$ at room temperature in the dark. The reactions were stop by adding $400 \mu \mathrm{l} 1 \times$ PBS and the samples were analyzed within $30 \mathrm{~min}$ using the Accuri C6 Flow Cytometer with CFlow ${ }^{\circledR}$ Software (BD Biosciences).

\section{Statistical analysis}

Student's $t$ test was used for all analyses. The data were presented as the mean \pm standard error of the mean (SEM). $\mathrm{p}<0.05$ was considered statistically significant.

\section{Supplementary Information}

The online version contains supplementary material available at https://doi. org/10.1186/s13578-021-00532-5.

Additional file 1: Figure S1. Pre-incubation of platelets with R11-S24 suppresses platelet spreading on fibrinogen during thrombin stimulation. Platelets were pre-incubated with R11, R11-S24 or R11-S24A peptide then stimulated with thrombin $(0.05 \mathrm{U} / \mathrm{ml})$ and were spread on coverslips. After spreading on coverslips, the platelets were fixed, permeabilized, stained for F-actin (green) and observed by phase contrast microscopy. 
Additional file 2: Figure S2. Pre-incubation of platelets with R1 1-S24 had no effect on thrombin-induced fibrinogen binding and platelet aggregation. Platelets were pre-incubated with R11, R11-S24 or R11-S24A peptide then stimulated with thrombin $(0.05 \mathrm{U} / \mathrm{ml})$. Fibrinogen binding was determined by flow cytometry. Platelet aggregation was recorded by a platelet aggregometer.

\section{Abbreviations}

BSA: Bovine serum albumin; CIN85: Cbl-interacting protein of $85 \mathrm{kDa}$; Dab2: Disabled-2; Dab2-pSer24: Dab2-Ser24 phosphorylation; NP-pep: Non-phosphorylated peptide; P-pep: Phosphorylated peptide; $\mathrm{PGI}_{2}$ : Prostaglandin $\mathrm{I}_{2}$; PKC: Protein kinase C; PLD1: Phospholipase D1; PMSF: Phenylmethylsulfonyl fluoride; PRP: Platelet-rich-plasma; RT: Room temperature; SDS-PAGE: Sodium dodecyl sulfate-polyacrylamide gel electrophoresis; SEM: Standard error of the mean; TPA: 12-O-tetradecanoylphorbol-13-acetate; TXA2: Thromboxane A2.

\section{Acknowledgements}

We appreciate Professor Arnold Stern (New York University School of Medicine) for the editorial help in the preparation of this manuscript.

\section{Authors' contributions}

Conceptualization, HJT and CPT; data curation, HJT, YHC, MLK, and HPC; data analysis, HJT, JCC, DPC, and CPT; writing-original draft preparation, HJT and CPT; writing-review and editing, HJT, JCC, DPC, KMR, HRL, and CPT; funding acquisition, JCC, KMR, and CPT. All authors read and approved the final manuscript.

\section{Funding}

This work was funded by the Chang Gung Medical Foundation [Grant Numbers CMRPG8F1621-3, CMRPD1H0211-3, CMRPD1 K0071-2, CORPD1 K0031, and BMRP466]; the Ministry of Science and Technology [Grant Number 1052314-B-182-042, 106-2320-B-182-027-MY3, and 109-2320-B-182-031-MY3]; the China Medical University Hospital [Grant Number CMU108-S-35 and CMU109-MF-67], and the E-Da Cancer Hospital [Grant Number EDCHP108002] to K.-M.R., C.P.T., and J.-C.C.

\section{Availability of data and materials}

All data in this study are available upon request.

\section{Ethics approval and consent to participate}

The study has been reviewed and approved by the Institutional Review Board of Chang Gung Memorial Hospital (Approval ID: 201601117A3). Written informed consent was obtained from the healthy volunteers.

\section{Consent for publication}

Not applicable.

\section{Competing interests}

The authors declare that they have no conflicts of interests.

\footnotetext{
Author details

${ }^{1}$ Department of Medical Biotechnology and Laboratory Science, College of Medicine, Chang Gung University, Taoyuan 333, Taiwan, Republic of China. ${ }^{2}$ Department of Medical Laboratory Science and Biotechnology, China Medical University, Taichung 404, Taiwan, Republic of China. ${ }^{3}$ Department of Laboratory Medicine, Chang Gung Memorial Hospital, Taoyuan 333, Taiwan, Republic of China. ${ }^{4}$ Department of Hematology-Oncology, E-Da Cancer Hospital, Kaohsiung 824, Taiwan, Republic of China. ${ }^{5}$ School of Medicine, College of Medicine, I-Shou University, Kaohsiung 824, Taiwan, Republic of China. ${ }^{6}$ Graduate institute of Natural Products, College of Medicine, Chang-Gung University, Taoyuan 333, Taiwan, Republic of China. ${ }^{7}$ Graduate institute of Biomedical Sciences, College of Medicine, Chang Gung University, Taoyuan 333, Taiwan, Republic of China. ${ }^{8}$ Department of Anesthesiology, Chang Gung Memorial Hospital, Taoyuan 333, Taiwan, Republic of China. ${ }^{9}$ Molecular Medicine Research Center, Chang Gung University, Taoyuan 333, Taiwan, Republic of China.
}

Received: 11 August 2020 Accepted: 5 January 2021

Published online: 08 February 2021

\section{References}

1. Huang J, Li X, Shi X, Zhu M, Wang J, Huang S, et al. Platelet integrin alphalIbbeta3: signal transduction, regulation, and its therapeutic targeting. J Hematol Oncol. 2019;12(1):26.

2. Scharf RE. Platelet signaling in primary haemostasis and arterial thrombus formation: Part 1. Hamostaseologie. 2018;38(4):203-10.

3. Scharf RE. Platelet signaling in primary haemostasis and arterial thrombus formation: Part 2. Hamostaseologie. 2018;38(4):211-22.

4. Shen B, Delaney MK, Du X. Inside-out, outside-in, and inside-outside-in: $G$ protein signaling in integrin-mediated cell adhesion, spreading, and retraction. Curr Opin Cell Biol. 2012;24(5):600-6.

5. Durrant TN, van den Bosch MT, Hers I. Integrin alphall bbeta3 outside-in signaling. Blood. 2017;130(14):1607-19.

6. Fender AC, Rauch BH, Geisler T, Schrör K. Protease-activated receptor PAR4: an inducible switch between thrombosis and vascular inflammation? Thromb Haemost. 2017;117(11):2013-25.

7. Jamasbi J, Ayabe K, Goto S, Nieswandt B, Peter K, Siess W. Platelet receptors as therapeutic targets: past, present and future. Thromb Haemost. 2017;117(7):1249-57.

8. Angiolillo DJ, Capodanno D, Goto S. Platelet thrombin receptor antagonism and atherothrombosis. Eur Heart J. 2010;31(1):17-28.

9. Rayes J, Watson SP, Nieswandt B. Functional significance of the platelet immune receptors GPVI and CLEC-2. J Clin invest. 2019;129(1):12-23.

10. Roca-Cusachs P, del Rio A, Puklin-Faucher E, Gauthier NC, Biais N, Sheetz MP. tegrin-dependent force transmission to the extracellular matrix by alpha-actinin triggers adhesion maturation. Proc Natl Acad Sci U S A. 2013;110(15):E1361-70.

11. Calderwood DA, Fujioka Y, de Pereda JM, Garcia-Alvarez B, Nakamoto T, Margolis B, et al. tegrin beta cytoplasmic domain interactions with phosphotyrosine-binding domains: a structural prototype for diversity in integrin signaling. Proc Natl Acad Sci U S A. 2003;100(5):2272-7.

12. Ratnikov Bl, Partridge AW, Ginsberg MH. tegrin activation by talin. J Thromb Haemost. 2005;3(8):1783-90.

13. Egot M, Kauskot A, Lasne D, Gaussem P, Bachelot-Loza C. Biphasic myosin II light chain activation during clot retraction. Thromb Haemost. 2013;110(6):1215-22.

14. Yeung J, Li W, Holinstat M. Platelet signaling and disease: targeted therapy for thrombosis and other related diseases. Pharmacol Rev. 2018;70(3):526-48.

15. Ley K, Rivera-Nieves J, Sandborn WJ, Shattil S. tegrin-based therapeutics: biological basis, clinical use and new drugs. Nat Rev Drug Discov. 2016;15(3):173-83.

16. El Alaoui MZ, Guy A, Khalki L, Limami Y, Benomar A, Zaid N, et al. Current antiplatelet agents, new inhibitors and therapeutic targets. Med Sci (Paris). 2020;36(4):348-57.

17. Bassler N, Loeffler C, Mangin P, Yuan Y, Schwarz M, Hagemeyer CE, et al. A mechanistic model for paradoxical platelet activation by ligand-mimetic alphallb beta3 (GPIllb/lla) antagonists. Arterioscler Thromb Vasc Biol. 2007;27(3):e9-15.

18. Huang $\mathrm{CL}$, Cheng JC, Liao CH, Stern A, Hsieh JT, Wang CH, et al. Disabled-2 is a negative regulator of integrin alpha(llb)beta(3)mediated fibrinogen adhesion and cell signaling. J Biol Chem. 2004;279(40):42279-89.

19. Huang CL, Cheng JC, Stern A, Hsieh JT, Liao CH, Tseng CP. Disabled-2 is a novel alphallb-integrin-binding protein that negatively regulates plateletfibrinogen interactions and platelet aggregation. J Cell Sci. 2006;1 19(Pt 21):4420-30.

20. Tsai HJ, Chien KY, Liao HR, Shih MS, Lin YC, Chang YW, et al. Functional links between Disabled-2 Ser723 phosphorylation and thrombin signaling in human platelets. J Thromb Haemost. 2017;15(10):2029-44.

21. Tsai HJ, Huang CL, Chang YW, Huang DY, Lin CC, Cooper JA, et al. Disabled-2 is required for efficient hemostasis and platelet activation by thrombin in mice. Arterioscler Thromb Vasc Biol. 2014;34(11):2404-12.

22. Drahos KE, Welsh JD, Finkielstein CV, Capelluto DG. Sulfatides partition disabled-2 in response to platelet activation. PLoS ONE. 2009;4(11):e8007. 
23. Welsh JD, Charonko JJ, Salmanzadeh A, Drahos KE, Shafiee H, Stremler MA, et al. Disabled-2 modulates homotypic and heterotypic platelet interactions by binding to sulfatides. Br J Haematol. 2011;154(1):122-33.

24. Xiao S, Charonko JJ, Fu X, Salmanzadeh A, Davalos RV, Vlachos PP, et al. Structure, sulfatide binding properties, and inhibition of platelet aggregation by a disabled-2 protein-derived peptide. J Biol Chem. 2012;287(45):37691-702.

25. He J, Xu J, Xu XX, Hall RA. Cell cycle-dependent phosphorylation of Disabled-2 by cdc2. Oncogene. 2003:22(29):4524-30.

26. Koral K, Li H, Ganesh N, Birnbaum MJ, Hallows KR, Erkan E. Akt recruits Dab2 to albumin endocytosis in the proximal tubule. Am J Physiol Renal Physiol. 2014;307(12):F1380-9.

27. Olsen JV, Vermeulen M, Santamaria A, Kumar C, Miller ML, Jensen LJ, et al. Quantitative phosphoproteomics reveals widespread full phosphorylation site occupancy during mitosis. Sci Signal. 2010;3(104):ra3.

28. Tseng CP, Ely BD, Pong RC, Wang Z, Zhou J, Hsieh JT. The role of DOC-2/ DAB2 protein phosphorylation in the inhibition of AP-1 activity. An underlying mechanism of its tumor-suppressive function in prostate cancer. J Biol Chem. 1999;274(45):31981-6.

29. Xu XX, Yang W, Jackowski S, Rock CO. Cloning of a novel phosphoprotein regulated by colony-stimulating factor 1 shares a domain with the Drosophila disabled gene product. J Biol Chem. 1995;270(23):14184-91.

30. Beck F, Geiger J, Gambaryan S, Solari FA, Dell'Aica M, Loroch S, et al. Temporal quantitative phosphoproteomics of ADP stimulation reveals novel central nodes in platelet activation and inhibition. Blood. 2017;129(2):e1-12.

31. Beausoleil SA, Villen J, Gerber SA, Rush J, Gygi SP. A probability-based approach for high-throughput protein phosphorylation analysis and site localization. Nat Biotechnol. 2006;24(10):1285-92.

32. Chetrit D, Barzilay L, Horn G, BielikT, Smorodinsky NI, Ehrlich M. Negative regulation of the endocytic adaptor disabled-2 (Dab2) in mitosis. J Biol Chem. 2011;286(7):5392-403.

33. Beausoleil SA, Jedrychowski M, Schwartz D, Elias JE, Villen J, Li J, et al. Large-scale characterization of HeLa cell nuclear phosphoproteins. Proc Natl Acad Sci U S A. 2004:101(33):12130-5.

34. Dephoure N, Zhou C, Villen J, Beausoleil SA, Bakalarski CE, Elledge SJ, et al. A quantitative atlas of mitotic phosphorylation. Proc Natl Acad Sci U S A. 2008;105(31):10762-7.

35. Cohen S, Braiman A, Shubinsky G, Ohayon A, Altman A, Isakov N. PKCtheta is required for hemostasis and positive regulation of thrombininduced platelet aggregation and alpha-granule secretion. Biochem Biophys Res Commun. 2009;385(1):22-7.

36. Donovan LE, Dammer EB, Duong DM, Hanfelt JJ, Levey Al, Seyfried NT, et al. Exploring the potential of the platelet membrane proteome as a source of peripheral biomarkers for Alzheimer's disease. Alzheimers Res Ther. 2013;5(3):32.

37. Joshi P, Riley DRJ, Khalil JS, Xiong H, Ji W, Rivero F. The membrane-associated fraction of cyclase associate protein 1 translocates to the cytosol upon platelet stimulation. Sci Rep. 2018;8(1):10804

38. Farrell DH, Thiagarajan $\mathrm{P}$, Chung DW, Davie EW. Role of fibrinogen alpha and gamma chain sites in platelet aggregation. Proc Natl Acad Sci U S A. 1992;89(22):10729-32.

39. Buensuceso CS, Obergfell A, Soriani A, Eto K, Kiosses WB, Arias-Salgado EG, et al. Regulation of outside-in signaling in platelets by integrin-associated protein kinase C beta. J Biol Chem. 2005;280(1):644-53.

40. Jirousek MR, Gillig JR, Gonzalez CM, Heath WF, McDonald JH 3rd, Neel DA, et al. (S)-13-[(dimethylamino)methyl]-10,11,14,15-tetrahydro-4,9:16,21dimetheno-1H, 13H-dibenzo[e, k]pyrrolo[3,4-h][1,4,13]oxadiazacyclohexadecene-1,3(2H)-dione (LY333531) and related analogues: isozyme selective inhibitors of protein kinase $\mathrm{C}$ beta. J Med Chem. 1996;39(14):2664-71.

41. Law DA, DeGuzman FR, Heiser P, Ministri-Madrid K, Killeen N, Phillips DR. tegrin cytoplasmic tyrosine motif is required for outside-in alphallbbeta3 signalling and platelet function. Nature. 1999;401(6755):808-11.

42. Kock LD, Freson K. The (patho)biology of SRC kinase in platelets and megakaryocytes. Medicina (Kaunas). 2020;56(12):E633.
43. Lu WJ, Chung CL, Chen RJ, Huang LT, Lien LM, Chang CC, et al. An antithrombotic strategy by targeting phospholipase $\mathrm{D}$ in human platelets. J Clin Med. 2018;7(11):440.

44. David T, Ohlmann P, Eckly A, Moog S, Cazenave JP, Gachet C, et al. hibition of adhesive and signaling functions of the platelet GPIb-V-IX complex by a cell penetrating GPIbalpha peptide. J Thromb Haemost. 2006:4(12):2645-55.

45. Pandey D, Goyal P, Dwivedi S, Siess W. Unraveling a novel Rac1-mediated signaling pathway that regulates cofilin dephosphorylation and secretion in thrombin-stimulated platelets. Blood. 2009;114(2):415-24.

46. Wei Q, Xia Y. Proteasome inhibition down-regulates endothelial nitric-oxide synthase phosphorylation and function. J Biol Chem. 2006;281(31):21652-9.

47. Cirit M, Grant KG, Haugh JM. Systemic perturbation of the ERK signaling pathway by the proteasome inhibitor, MG132. PLOS ONE. 2012;7(11):e50975

48. Chiang-Ni C, Kao CY, Hsu CY, Chiu CH. Phosphorylation at the D53 but not the $\mathrm{T} 65$ residue of CovR determines the repression of rgg and speB transcription in emm 1- and emm49-Type Group A Streptococci. J Bacteriol. 2019;201(4):e00681-e718.

49. Guthridge MA, Powell JA, Barry EF, Stomski FC, McClure BJ, Ramshaw H, et al. Growth factor pleiotropy is controlled by a receptor Tyr/Ser motif that acts as a binary switch. EMBO J. 2006;25(3):479-89.

50. Harper MT, Poole AW. Diverse functions of protein kinase $C$ isoforms in platelet activation and thrombus formation. J Thromb Haemost. 2010;8(3):454-62

51. Konopatskaya O, Gilio K, Harper MT, Zhao Y, Cosemans JM, Karim ZA, et al. PKCalpha regulates platelet granule secretion and thrombus formation in mice. J Clin invest. 2009;119(2):399-407.

52. Yacoub D, Theoret JF, Villeneuve L, Abou-Saleh H, Mourad W, Allen $B G$, et al. Essential role of protein kinase $C$ delta in platelet signaling, alpha IIb beta 3 activation, and thromboxane A2 release. J Biol Chem. 2006;281(40):30024-35.

53. Cohen S, Braiman A, Shubinsky G, Isakov N. Protein kinase C-theta in platelet activation. FEBS Lett. 2011;585(20):3208-15.

54. Bynagari YS, Nagy B Jr, Tuluc F, Bhavaraju K, Kim S, Vijayan KV, et al. Mechanism of activation and functional role of protein kinase Ceta in human platelets. J Biol Chem. 2009;284(20):13413-21.

55. Ahn SJ, Yoon MS, Hyuk S, Han W, Yoon YD, Han JS, et al. Phospholipase C-protein kinase $\mathrm{C}$ mediated phospholipase $\mathrm{D}$ activation pathway is involved in tamoxifen induced apoptosis. J Cell Biochem. 2003:89(3):520-8.

56. Parmentier JH, Smelcer P, Pavicevic Z, Basic E, Idrizovic A, Estes A, et al. PKC-zeta mediates norepinephrine-induced phospholipase D activation and cell proliferation in VSMC. Hypertension. 2003;41(3 Pt 2):794-800.

57. Vorland $M$, Thorsen VA, Holmsen H. Phospholipase D in platelets and other cells. Platelets. 2008;19(8):582-94.

58. Tsai HJ, Tseng CP. The adaptor protein Disabled-2: new insights into platelet biology and integrin signaling. Thromb J. 2016;14(Suppl 1):28

59. Lee HY, Yu NY, Lee SH, Tsai HJ, Wu CC, Cheng JC, et al. Podoplanin promotes cancer-associated thrombosis and contributes to the unfavorable overall survival in an ectopic xenograft mouse model of oral cancer. Biomed J. 2020:43(2):146-62.

60. Lin JD, Liou MJ, Hsu HL, Leong KK, Chen YT, Wang YR, et al. Circulating epithelial cell characterization and correlation with remission and survival in patients with thyroid cancer. Thyroid. 2018;28(11):1479-89.

61. Chang YW, Hsieh PW, Chang YT, Lu MH, Huang TF, Chong KY, et al. Identification of a novel platelet antagonist that binds to CLEC-2 and suppresses podoplanin-induced platelet aggregation and cancer metastasis. Oncotarget. 2015;6(40):42733-48.

\section{Publisher's Note}

Springer Nature remains neutral with regard to jurisdictional claims in published maps and institutional affiliations. 